RECERVD

DOE/ID//2945-T10

JUH 24 \$S@

OSTI

\title{
A STUDY OF HYDROCARBONS ASSOCLATED WITH BRINES FROM DOE GEOPRESSURED WELLS
}

COOPERATIVE AGREEMENT: DE-FC07-90ID12945

FINAL REPORT

Dean F. Keeley, Ph.D.

Professor of Chemistry

Acadiana Research Laboratory (ARL)

The University of Southwestern Louisiana (USL)

Lafayette, LA 70504 


\section{DISCLAIMER}

This report was prepared as an account of work sponsored by an agency of the United States Government. Neither the United States Government nor any agency Thereof, nor any of their employees, makes any warranty, express or implied, or assumes any legal liability or responsibility for the accuracy, completeness, or usefulness of any information, apparatus, product, or process disclosed, or represents that its use would not infringe privately owned rights. Reference herein to any specific commercial product, process, or service by trade name, trademark, manufacturer, or otherwise does not necessarily constitute or imply its endorsement, recommendation, or favoring by the United States Government or any agency thereof. The views and opinions of authors expressed herein do not necessarily state or reflect those of the United States Government or any agency thereof. 


\section{DISCLAIMER}

Portions of this document may be illegible in electronic image products. Images are produced from the best available original document. 


\section{A STUDY OF HYDROCARBONS ASSOCIATED WITH BRINES}

FROM DOE GEOPRESSURED WELLS

COOPERATIVE AGREEMENT: DE-FC07-90ID12945

FINAL REPORT

Dean F. Keeley, Ph.D.
Professor of Chemistry

\section{DISCLAIMER}

This report was prepared as an account of work sponsored by an agency of the United States Government. Neither the United States Government nor any agency thereof, nor any of their employees, makes any warranty, express or implied, or assumes any legal liability or responsibility for the accuracy, completeness, or usefulness of any information, apparatus, product, or process disclosed, or represents that its use would not infringe privately owned rights. Reference herein to any specific commercial product, process, or service by trade name, trademark, manufacturer, or otherwise does not necessarily constitute or imply its endorsement, recommendation, or favoring by the United States Government or any agency thereof. The views and opinions of authors expressed herein do not necessarily state or reflect those of the United States Government or any agency thereof.

Acadiana Research Laboratory (ARL) The University of Southwestern Louisiana (USL) Lafayette, LA 70504 


$$
\text { ii }
$$

i

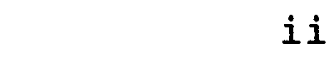




\section{Table of Contents}

Page

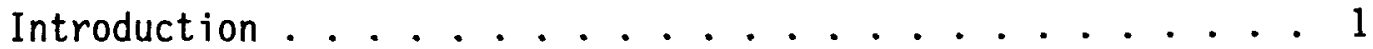

A. Distribution Coefficients and Solubilities ...... 5

B. DOE Design Well Sampling ............ 21

C. Analysis of Well Samples ............ . 25

D. Review of Theoretical Models of Geopressured Reservoir Hydrocarbons . . . . . . . . . . 27

E. Monitor for Aliphatic Hydrocarbons .........43

F. Development of a pH Meter Probe .......... . 45

G. Perform DOE Design Well Scrubber Analysis ....... 53

H. Removal and Disposition of Gas Scrubber Equipment at Pleasant Bayou Well . . . . . . . . . 57

I. Disposition of Archived Brines ......... . 59

Appendix A: Computer Programs ............61

Supplement A: Adsorption of Aromatic Compounds on Iron . . . 69 


\section{INTRODUCTION}

\section{Period Covered}

This final report covers the time frame March 27, 1990 through December 31, 1992, the period of activity of Cooperative Agreement DE-FCO7-90ID12945.

In certain instances data will be included, for clarity, which predates the above time period of the Cooperative Agreement.

\section{Assigned Tasks}

Over the time period of the Cooperative Agreement the tasks performed are listed in Table 1 with their time frames.

Table 1. Tasks performed under Cooperative Agreement DE-FC07-90ID12945 from March 27, 1990 through December 31, 1992.

\section{Task}

$\begin{array}{rrr}\text { Time } \frac{\text { Period }}{1 / 4 / 91} & 1 / 4 / 92 \\ 3 / 27 / 90 & 1 / 31 / 91 & 12 / 31 / 92\end{array}$

A. Distribution Coefficients and Solubilities

B. DOE Design Well Sampling

C. Analysis of Well Samples

$x$

$\begin{array}{lll}x & x & x \\ x & x\end{array}$

D. Review of Theoretical Models of Geopressured

$x$

$x \quad x$

Reservoir Hydrocarbons

E. Monitor for Aliphatic Hydrocarbons

F. Development of a $\mathrm{pH}$ Meter Probe

$\begin{array}{ll}x & x \\ x & x\end{array}$

G. Perform DOE Design Well Scrubber Analysis

$x$
$x$

$\mathrm{X}$

$x$

H. Removal and Disposition of Gas Scrubber Equipment at Pleasant Bayou Well

I. Disposition of Archived Brines

$x$

$x$ 
Detailed Description of Tasks

The following are the detailed DOE descriptions of the assigned tasks:

\section{A. Distribution Coefficients and Solubilities}

USL shall continue determinations of the distribution coefficients and solubilities of the principal aromatic constituents in the brines. These measurements will be made both as a function of temperature and ionic strength of the aqueous phase.

\section{B. DOE Design Well Sampling}

USL shall collect the cryogenically condensable hydrocarbons from the gas streams and brine samples at the Pleasant Bayou Well monthly. All necessary treatment and preparation will be done at the site to ensure validity of subsequent analytical results.

\section{Analysis of Well Samples}

USL shall analyze the samples taken from wells by gas chromatography (sic) to determine the type and amount of cryocondensate hydrocarbons in the formation brine. Monitoring of variations in these hydrocarbon concentrations as a function of the production volume will continue.

\section{Review of Theoretical Models of Geopressured Reservoir Hydrocarbons}

USL shall develop a review of theoretical models of geopressured reservoir hydrocarbons from published 1iterature. This review will serve as a foundation for the development and extension of theoretical models planned in the following task.

\section{E. Monitor for Aliphatic Hydrocarbons}

USL shall continue to study and to monitor the brine streams of geopressured wells for the production of aliphatic hydrocarbons. Hydrocarbon yields will be correlated with well operating parameters. This information will be used to develop and extend theoretical models of reservoir hydrocarbons. Experimental tests will be suggested to verify or reject the theoretical model. 
F. Development of a $\mathrm{pH}$ Meter Probe

USL shall continue development of an in-line $\mathrm{pH}$ measuring probe, based upon ion sensitive field effect transistor (ISFET) technology. This probe is intended to function at high ionic strength, temperature, and pressure.

\section{G. Perform DOE Design Well Scrubber Analysis}

USL shall prepare gas scrubber bottles and leave them for well-site personnel to insert and exchange each day in the USL designed collection apparatus. USL shall recover all daily samples on its regular visits and return them to their laboratory for gas chromatographic analysis for benzene and toluene.

\section{H. Removal and Disposition of Gas Scrubber Equipment at Pleasant Bayou Well}

This equipment consists of several feet of two inch piping and pressure regulators that is of no value to DOE due to its specialized design.

\section{Disposition of Archived Brines}

USL has collected approximately 95 gallons of investigation derived brines from DOE geopressured well sites and transported these brines to USL where they are currently being stored. DOE recommends that USL dispose of these brines in a manner consistent with best management practices consistent with state and Federal regulations regarding the disposition of these brines. 


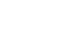
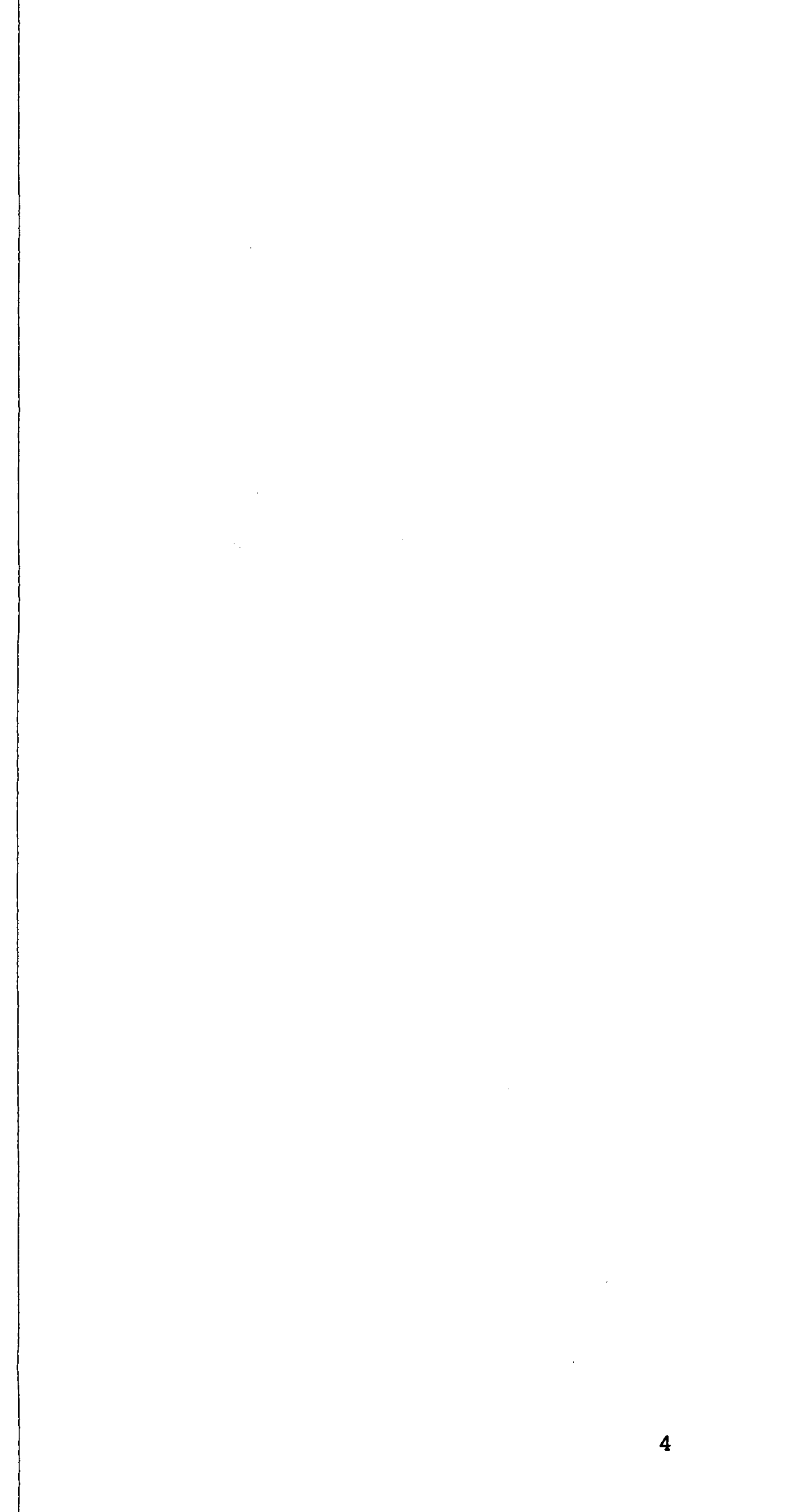


\section{RESULTS OF TASKS}

\section{A. Distribution Coefficients and Solubilities}

Determining solubilities of substances with appreciable vapor pressures can be complicated by the partition of such substances between the solvent and free gas space present above the solvent. A modification of the headspace analysis technique developed by Massaldi and King (1973) was selected as the method used for this study because of its ease of execution and because solute partition is not a problem since headspace methods make use of partition.

\section{A.1. Theory}

Volatile solutes tend to obey Henry's law

$$
p=k x
$$

The Henry's law constant is dependent upon the solute, solvent, and temperature but is independent of $x$ over the range for which the law holds. Since conformity with Henry's law increases as $x \rightarrow 0$, substances of limited solubilities tend to obey it over their solubility range.

When a sample from above a solution of a volatile solute, which obeys Henry's law, is analyzed by gas chromatography (GC) the peak area of the solute is directly proportional to its mole fractions in both the vapor and solution through the relationship

$$
A=C y=C x / K_{p}
$$

The total number of moles of solute in the system is given by

$$
n_{s}=n_{x}+n_{y}
$$

If $n_{S}^{0}$ and $n_{y}^{0}$ can be determined then, $n_{x}^{0}$, can be computed. The method of Massaldi and King was modified, in part, in the way $n_{s}^{0}$ was determined.

Table A.I defines the terms used in this section of the final report. 
Table A.I. Symbols employed ${ }^{a}$

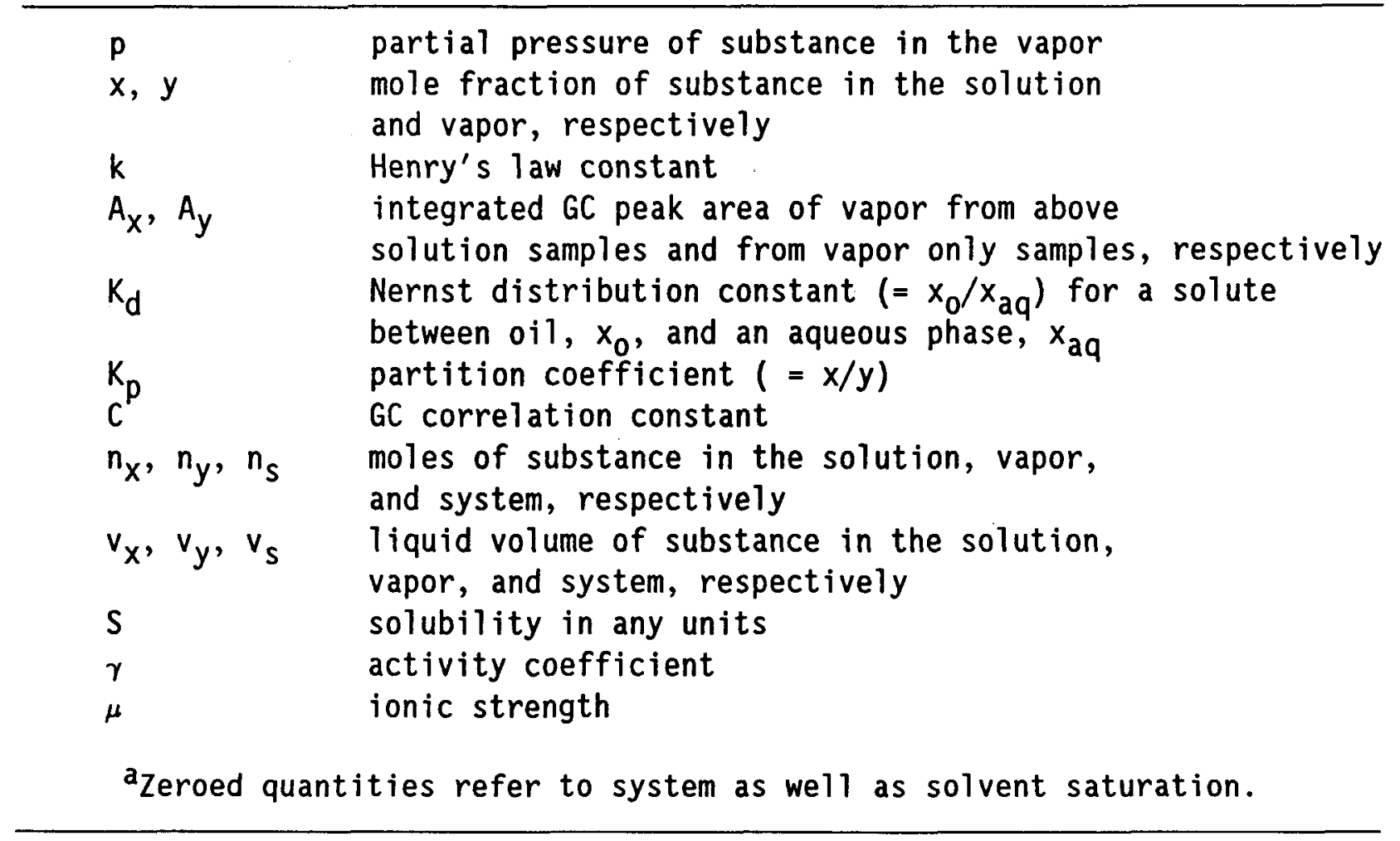

\section{A.2. Experimental}

A.2.a. Instrumentation. Measurements were made using a headspace attachment constructed specifically for a Varian Model 3700 gas chromatograph (Keeley, 1986).

A.2.b. Materials. The aromatic compounds used in this study were analyzed by gas chromatography prior to use. One sample of benzene (Baker InstraAnalyzed grade, 99.97\%), one sample of toluene (Baker Instra-Analyzed grade, 99.83\%), one sample of 1,2-dimethylbenzene (Aldrich Gold Label - 99.8\%), two samples of 1,3-dimethylbenzene (Baker - $99.60 \%$ and Aldrich - 99.8\%), and two samples of 1,4-dimethylbenzene (Baker - $99.78 \%$ and Aldrich Gold Label $99.83 \%)$, were used without further purification. Samples of 1,2-dimethylbenzene and ethylbenzene (Baker) were fractionally distilled to a purity of $99.80 \%$ and $99.40 \%$, respectively, prior to use. Sodium chloride (Baker Analyzed Reagent grade) was dried at $383 \mathrm{~K}$ prior to use. The deionized water used had a conductivity of $<10^{-6}(\Omega \mathrm{cm})^{-1}$ at $298.2 \mathrm{~K}$.

A.2.c. Sample Preparation. Samples were prepared in $125-\mathrm{cm}^{3}$ septum bottles (Wheaton "400" clear glass) which have a mean volume of $160.1 \pm 0.9$ $\mathrm{cm}^{3}$ at room temperature. Three types of samples were used: One contained 50.00 
$\mathrm{cm}^{3}$ of water or aqueous $\mathrm{NaCl}$ solution plus the hydrocarbon of interest, the second contained $50.00 \mathrm{~cm}^{3}$ of Mobil-1 0il plus the hydrocarbon of interest, the hydrocarbon was added from a microliter syringe (Hamilton Model 700 RN), the last sample contained only hydrocarbon vapor. A small $6.4 \mathrm{~mm}$ by $22.2 \mathrm{~mm}$ Pyrex glass stirring bar with a mean volume of $0.70 \mathrm{~cm}^{3}$ (Bel-Art Products) was present in the liquid samples. The bottles were sealed using poly(tetrafluoroethylene) coated silicone septa (Ace Tuf-Bond) and aluminum seals (Wheaton). Tin foil was placed between the septum and the bottle's contents in order to preclude absorption of hydrocarbon by the septa (Keeley, 1986). All preparations were carried out in an air-conditioned laboratory at $293 \mathrm{~K}$. The densities of the brine solutions were determined at 20 and $298.2 \mathrm{~K}$ and the density ratio was employed to adjust the results from preparative to experimental temperature. The bottles were thermostated $(298.2 \pm 0.01 \mathrm{~K}$ and shaken for 72 hours prior to analysis. For analys is each bottle was transferred to a tempering beaker and pressurized to $15.00 \pm 0.02$ psig with chromatographic grade nitrogen.

A.2.d. Analytical Procedure. Bottles were attached to the headspace attachment by piercing their septa with a side-port needle (Precision Sampling Corp.), an integral part of the headspace unit. Bottle and tempering beaker were supported on a magnetic stirrer (Cole-Parmer Micro-V). Vapor flow, 2-3 $\mathrm{mL} / \mathrm{min}$, through the sampling valve (Valco, 6-port) and sample loop (430 $\mu \mathrm{L})$ was controlled by a fine metering valve (Nupro $M$ series with vernier handle). The sampling valve was connected to a $1 \mathrm{~m}$ by $3.2 \mathrm{~mm}$ stainless steel GC column (5\% SP-1200, 1.75\% Bentone-34 on 100/120 mesh Supelcoport (Supelco Inc.)) and then to a flame ionization detector (FID).

To determine the hydrocarbon solubility, concentration of hydrocarbon in the vapor in equilibrium with hydrocarbon in solution must be known (Equation 2). Any vapor removal produces a pressure drop which disturbs this equilibrium. To obtain the equilibrium concentration, a multiple injection interrupted flow technique (MIIF) was developed. A series of vapor aliquots were taken at known flow times and a linear extrapolation of their GC responses made to obtain equilibrium conditions. The pneumatic compartment of the $G C$ and the headspace attachment were heated to $333 \mathrm{~K}$ to minimize hydrocarbon condensation or adsorption in the system.

Sampling schedules and integrator events were time coordinated to assure optimum integrator operation. Table A.II gives GC data for a typical run using the MIIF technique. The increase in peak area with flow time results from the partial pressure drop with vapor removal and desorption of solute from solution to reestablish equilibrium. The increase in mole fraction of hydrocarbon in the vapor occurs since other gases present are not replenished. Column "zero" under "Time" in Table A.II is from linear least-squares analysis of the time data. Column " $R$ " are the linear correlation coefficients of the data that 
produced each "zero" time value. The mean correlation coefficients for the "zero" time versus hydrocarbon volume plots used in this study was $0.9996 \pm 0.0005$ (s.d.m.).

Table A.II. GC response for toluene in $50.0 \mathrm{~cm}^{3}$ of water at $298.2 \mathrm{~K}$.

\begin{tabular}{rccccccc}
\hline $\begin{array}{c}\text { Solute } \\
\mathrm{mm}^{3}\end{array}$ & \multicolumn{8}{c}{ Time, min } \\
\cline { 2 - 8 } & 2 & 3 & 4 & 5 & 6 & zero & $\mathrm{R}$ \\
\hline 8 & 154342 & 156297 & 158200 & 160190 & 162355 & 150309 & 1.000 \\
16 & 308654 & 314154 & 319225 & 323508 & 327382 & 299861 & 0.997 \\
24 & 472932 & 479951 & 485355 & 490065 & 496379 & 462133 & 0.998 \\
32 & 635610 & 641182 & 648660 & 655351 & 662436 & 621907 & 1.000 \\
40 & 806111 & 814576 & 822442 & 830434 & 839307 & 789674 & 1.000 \\
\hline
\end{tabular}

Analysis of samples that contained only hydrocarbon vapor was carried out using the same procedure. The absence of liquid gave peaks of essentially constant size, and mean peak areas were used.

A.2.e. Data Reduction. The GC area response of the vapor-only samples was analyzed by least-squares as a function of volume of hydrocarbon to obtain

$$
A_{y}=m_{y} v_{y}+b_{y}
$$

The value of $A_{y}^{0}$ was computed from Equation 4, using the vapor volume, hydrocarbon density, hydrocarbon partial pressure based on ideal behavior and vapor pressure of pure hydrocarbon, $p^{0}$, computed from the Antoine equation (Dean, 1979). A least-squares analysis of data for vapor from above the solutions gave a similar relationship

$$
A_{x}=m_{s} v_{s}+b_{s}
$$

For the aqueous solutions at system saturation. $A_{x}=A_{y}^{0}, v_{s}=v_{s}^{0}$, and $v_{x}^{0}=v_{s}^{0}-v_{y}^{0}$. The value for $v_{y}^{0}$ was computed from the vapor volume and $p^{0}$. Concentrations were computed from $v_{X}^{0}$, compound and solution densities, and solution volume and composition. Figure A.l is a typical plot of the GC responses for vapor only and for liquid containing samples used to calculate $A_{y}^{0}$ and $v_{s}^{0}$. 
For the aqueous, aq, and oil, o, containing samples

$$
\begin{aligned}
& p_{a q}=k_{a q} x_{a q} \\
& p_{0}=k_{0} x_{0}
\end{aligned}
$$

when $p_{a q}=p_{0}, \quad k_{a q} x_{a q}=k_{0} x_{0}$ and

$$
x_{0} / x_{a q}=k_{a q} / k_{0}=k_{d}
$$

where $K_{d}$ is the Nernst distribution constant.

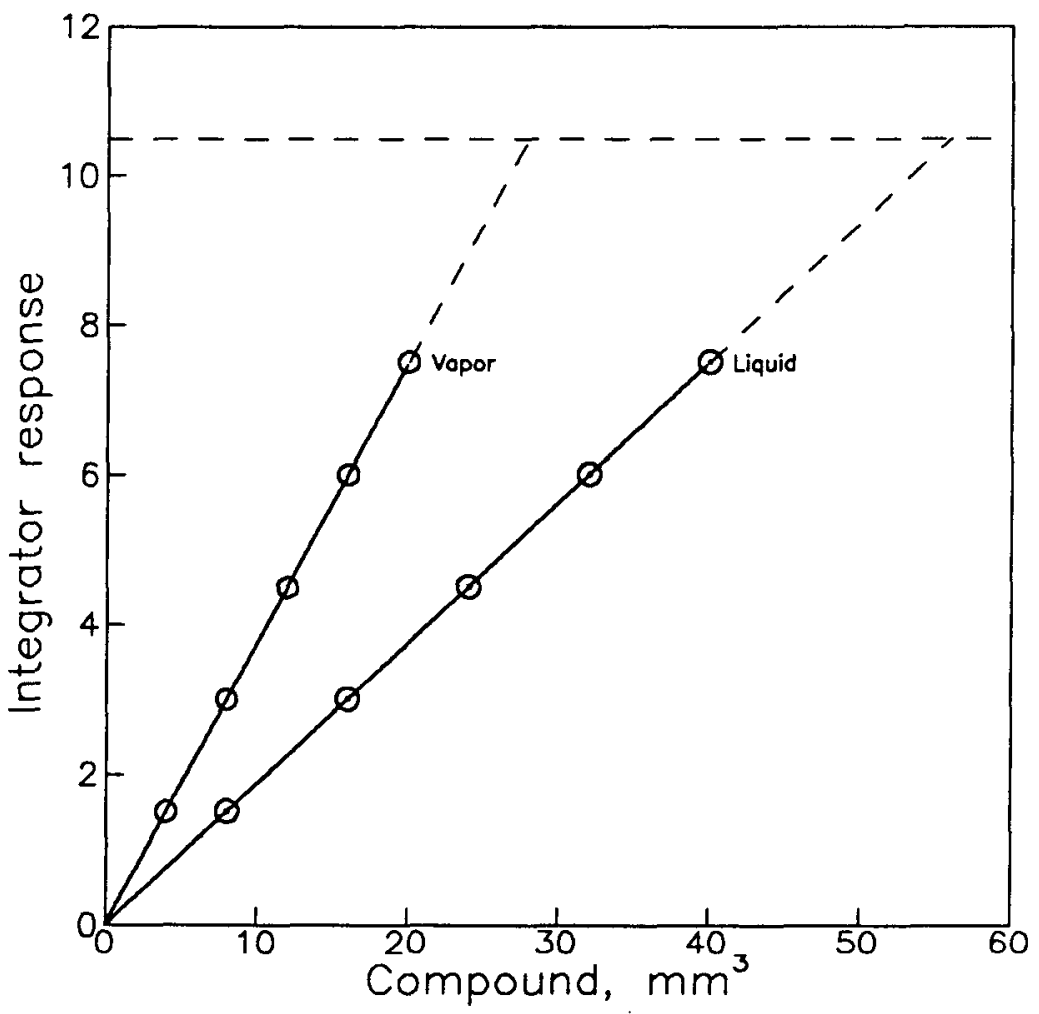

Figure A.1. Typical "zero" flow time GC response as a function of microliters of hydrocarbon. $O=$ vapor only samples. $\odot=$ liquid containing samples. The horizontal dashed line corresponds to system saturation.

\section{A.3. Results.}

Solubilities, Henry's law constants and aqueous/vapor partition coefficients for benzene, toluene, ethylbenzene, 1,2-, 1,3-, and 1,4-dimethylbenzene are given in Tables A.III through A.VIII, respectively, for aqueous $\mathrm{NaCl}$ solutions with ionic strength, $\mu=0$ to 5.00 . 
Table A.III. Molar solubilities, Henry's law constants, $k$, partition coefficients, $K_{p}$, and Nernst distribution constants, $K_{d}$, for benzene in water and aqueous sodium chloride at $298.2 \mathrm{~K}$

\begin{tabular}{cccccc}
\hline $\begin{array}{c}\mu / \\
\left(\mathrm{mol}^{\prime} \mathrm{dm}^{-3}\right)\end{array}$ & $\left(10^{-3} \mathrm{~S} /\right.$ \\
$\left.\mathrm{mol} \mathrm{dm}^{-3}\right)$ & $\left(10^{7 /} \mathrm{Pa}\right)$ & $\mathrm{Kp}^{\dagger \dagger}$ & $\begin{array}{c}\mathrm{K}_{\mathrm{d}}^{\dagger \dagger \dagger} \\
\left(10^{2}\right)\end{array}$ \\
\hline 0 & $21.7 \pm 0.00$ & $3.25 \pm 0.00$ & $4.23 \pm 0.00$ & $1.76 \pm 0.00$ \\
1 & $12.9 \pm 0.10$ & $5.45 \pm 0.03$ & $2.52 \pm 0.02$ & $2.94 \pm 0.10$ \\
2 & $9.21 \pm 0.08$ & $7.64 \pm 0.07$ & $1.80 \pm 0.01$ & $4.23 \pm 0.30$ \\
3 & $6.13 \pm 0.02$ & $15.5 \pm 0.0$ & $1.20 \pm 0.01$ & $6.42 \pm 0.02$ \\
4 & $3.69 \pm 0.16$ & $19.1 \pm 0.2$ & $0.720 \pm 0.032$ & $10.3 \pm 0.4$ \\
5 & $2.57 \pm 0.04$ & $27.3 \pm 0.4$ & $0.503 \pm 0.007$ & $14.8 \pm 0.2$ \\
\hline
\end{tabular}

$\dagger p=k x$ where $x=$ solute mole fraction, $p=$ solute partial pressure in pascals.

t† $K_{p}=x / y$ where $x$ and $y=$ solute mole fraction in the solution and vapor, respectively.

${ }^{\dagger \dagger}+k_{d}=k_{a} / k_{0}$ where $k_{a}$ and $k_{0}$ are the Henry's law constants for the aqueous and oil solutions, respectively.

Table A.IV. Molar solubilities, Henry's law constants, $k$, partition coefficients, $K_{p}$, and Nernst distribution constants, $K_{d}$, for toluene in water and aqueous sodium chloride at $298.2 \mathrm{~K}$

\begin{tabular}{ccccccc}
\hline $\begin{array}{c}\mu / \\
\left(\mathrm{mol} \mathrm{dm}^{-3}\right)\end{array}$ & $\begin{array}{c}\mathrm{S} / \\
\left(10^{-3} \mathrm{~mol} \mathrm{dm}^{-3}\right)\end{array}$ & $\begin{array}{c}\mathrm{k} / \\
\left(10^{7} \mathrm{~Pa}\right)\end{array}$ & $\mathrm{Kp}_{\mathrm{p}}$ & $\begin{array}{c}\mathrm{K}_{\mathrm{d}} / \\
\left(10^{2}\right)\end{array}$ \\
\hline 0 & $6.29 \pm 0.05$ & $3.36 \pm 0.03$ & $4.10 \pm 0.03$ & $4.77 \pm 0.04$ \\
1 & $3.86 \pm 0.05$ & $5.43 \pm 0.07$ & 2.52 & \pm 0.03 & $8.57 \pm 0.10$ \\
2 & $2.21 \pm 0.01$ & $9.49 \pm 0.03$ & $1.44 \pm 0.01$ & $13.6 \pm 0.0$ \\
3 & $1.50 \pm 0.04$ & $14.0 \pm 0.3$ & $0.975 \pm 0.024$ & 23.1 & \pm 0.6 \\
4 & $0.892 \pm 0.026$ & $23.3 \pm 0.7$ & $0.582 \pm 0.017$ & $37.2 \pm 1.1$ \\
5 & $0.638 \pm 0.024$ & $32.4 \pm 1.2$ & $0.416 \pm 0.017$ & $50.8 \pm 1.9$ \\
\hline
\end{tabular}


Table A.V. Molar solubilities, Henry's law constants, $k$, partition coefficients, $K_{p}$, and Nernst distribution constants, $K_{d}$, for ethylbenzene in water and aqueous sodium chloride at $298.2 \mathrm{~K}$

\begin{tabular}{cccccc}
\hline $\begin{array}{c}\mu / \\
\left(\mathrm{mol} \mathrm{dm}^{-3}\right)\end{array}$ & $\begin{array}{c}\mathrm{S} / \\
\left(10^{-3} \mathrm{~mol} \mathrm{dm}^{-3}\right)\end{array}$ & $\begin{array}{c}\mathrm{k} / \\
\left(10^{7} \mathrm{~Pa}\right)\end{array}$ & $K_{\mathrm{p}}$ & $\begin{array}{c}K_{\mathrm{d}} / 2 \\
\left(10^{2}\right)\end{array}$ \\
\hline 0 & $1.66 \pm 0.04$ & $4.24 \pm 0.11$ & $3.24 \pm 0.08$ & $15.0 \pm 0.0$ \\
1 & $1.01 \pm 0.05$ & $6.95 \pm 0.35$ & 1.98 & \pm 0.09 & $22.3 \pm 1.3$ \\
2 & $0.549 \pm 0.023$ & $12.7 \pm 0.52$ & $1.07 \pm 0.05$ & $38.3 \pm 1.6$ \\
3 & $0.387 \pm 0.007$ & $18.0 \pm 0.27$ & $0.755 \pm 0.014$ & $64.5 \pm 1.2$ \\
4 & $0.202 \pm 0.007$ & $28.7 \pm 1.1$ & $0.473 \pm 0.018$ & $97.5 \pm 3.7$ \\
5 & $0.148 \pm 0.015$ & $47.1 \pm 4.8$ & $0.289 \pm 0.029$ & $162 \pm 16$ \\
\hline
\end{tabular}

Table A.VI. Molar solubilities, Henry's law constants, $k$, partition coefficients, $K_{p}$, and Nernst distribution constants, $K_{d}$, for 1,2-dimethylbenzene in water and aqueous sodium chloride at $298.2 \mathrm{~K}$

\begin{tabular}{ccccccc}
\hline $\begin{array}{c}\mu / \\
\left(\mathrm{mol}^{2} \mathrm{dm}^{-3}\right)\end{array}$ & $\begin{array}{c}\mathrm{S} / \\
\left(10^{-3} \mathrm{~mol} \mathrm{dm}^{-3}\right)\end{array}$ & $\begin{array}{c}\mathrm{k} / \\
\left(10^{7} \mathrm{~Pa}\right)\end{array}$ & $K_{\mathrm{p}}$ & $\begin{array}{c}K_{\mathrm{d}} / \\
\left(10^{2}\right)\end{array}$ \\
\hline 0 & $2.09 \pm 0.05$ & $2.39 \pm 0.08$ & $5.69 \pm 0.16$ & $11.5 \pm 0.3$ \\
1 & $1.17 \pm 0.05$ & $4.19 \pm 0.19$ & 3.28 & \pm 0.16 & $22.4 \pm 1.1$ \\
2 & $0.637 \pm 0.004$ & $7.67 \pm 0.04$ & $1.70 \pm 0.01$ & $35.9 \pm 0.2$ \\
3 & $0.419 \pm 0.012$ & $11.6 \pm 0.39$ & $1.18 \pm 0.03$ & $58.9 \pm 2.3$ \\
4 & $0.241 \pm 0.030$ & $20.5 \pm 2.8$ & $0.673 \pm 0.096$ & $93.8 \pm 8.7$ \\
5 & $0.121 \pm 0.021$ & $41.9 \pm 4.8$ & $0.341 \pm 0.059$ & 214 & \pm 36 \\
\hline
\end{tabular}

Table A.VII. Molar solubilities, Henry's law constants, $k$, partition coefficients, $K_{p}$, and Nernst distribution constants, $K_{d}$, for 1,3-dimethylbenzene in water and aqueous sodium chloride at $298.2 \mathrm{~K}$

\begin{tabular}{|c|c|c|c|c|c|c|c|}
\hline$\stackrel{\mu /}{\left(\mathrm{mol}^{-3} \mathrm{dm}^{-3}\right)}$ & $\left(10^{-3} \mathrm{~mol}\right.$ & $\left.\mathrm{dm}^{-3}\right)$ & $\left(10^{\frac{k}{7}}\right.$ & ' $\mathrm{Pa}$ & & $K_{p}$ & $\begin{array}{l}k_{d} / 2 \\
\left(10^{2}\right)\end{array}$ \\
\hline 0 & 1.58 & \pm 0.02 & $3.89 \pm$ & \pm 0.04 & 3.53 & \pm 0.04 & $16.5 \pm 0.4$ \\
\hline 1 & 0.923 & \pm 0.032 & $6.64 \pm$ & \pm 0.23 & 2.06 & \pm 0.07 & $25.9 \pm 0.9$ \\
\hline 2 & 0.567 & \pm 0.011 & $10.8 \pm$ & \pm 0.20 & 1.27 & \pm 0.03 & $41.9 \pm 0.8$ \\
\hline 3 & 0.294 & \pm 0.015 & $20.7 \pm$ & \pm 1.2 & 0.659 & \pm 0.033 & $71.6 \pm 3.8$ \\
\hline 4 & 0.179 & \pm 0.007 & $33.9 \pm$ & \pm 1.2 & 0.401 & \pm 0.015 & $152 \pm 5$ \\
\hline 5 & 0.0957 & \pm 0.0021 & $62.9 \pm$ & \pm 1.3 & 0.214 & \pm 0.005 & 283 \\
\hline
\end{tabular}


Table A.VIII. Molar solubilities, Henry's law constants, k, partition coefficients, $K_{p}$, and Nernst distribution constants, $K_{d}$, for 1,4-dimethylbenzene in water and aqueous sodium chloride at $298.2 \mathrm{~K}$

\begin{tabular}{ccccccc}
\hline $\begin{array}{c}\mu / \\
\left(\mathrm{mol} \mathrm{dm}^{-3}\right)\end{array}$ & $\begin{array}{c}\mathrm{S} / \\
\left(10^{-3} \mathrm{~mol} \mathrm{dm}^{-3}\right)\end{array}$ & $\left(10^{7} \mathrm{~Pa}\right)$ & $K_{\mathrm{p}}$ & $\begin{array}{c}K_{\mathrm{d}} / \\
\left(10^{2}\right)\end{array}$ \\
\hline 0 & $1.63 \pm 0.02$ & $3.97 \pm 0.05$ & $3.46 \pm 0.05$ & $15.3 \pm 0.2$ \\
1 & $0.846 \pm 0.019$ & $7.63 \pm 0.17$ & $1.79 \pm 0.04$ & $34.1 \pm 0.7$ \\
2 & $0.512 \pm 0.010$ & $12.6 \pm 0.25$ & $1.09 \pm 0.02$ & $52.0 \pm 1.0$ \\
3 & $0.288 \pm 0.006$ & $22.4 \pm 0.40$ & $0.611 \pm 0.012$ & $98.9 \pm 1.9$ \\
4 & $0.152 \pm 0.005$ & $42.1 \pm \pm 1.5$ & $0.322 \pm 0.011$ & 183 & \pm 7 \\
5 & $0.109 \pm 0.015$ & $60.8 \pm \pm 4.7$ & $0.223 \pm 0.017$ & 302 & \pm 24 \\
\hline
\end{tabular}

Table A.IX contains a summary of the aqueous solubilities of benzene and its $C_{1}$ and $C_{2}$ alkyl substituted derivatives at several temperatures.

Table A.IX. Aqueous solubilities $\left(S / 10^{-3} \mathrm{~mol} \mathrm{dm^{3 }}\right)$ for benzene and it $C_{1}$ and $C_{2}$ alkyl substituted derivatives at several temperatures.

\begin{tabular}{lcccc}
\hline & $298.2 \mathrm{~K}$ & $313.2 \mathrm{~K}$ & $328.2 \mathrm{~K}$ & $343.2 \mathrm{~K}$ \\
\hline Benzene & 21.7 & 24.5 & 28.1 & 34.4 \\
Toluene & 6.29 & 6.46 & 7.75 & 9.20 \\
Ethylbenzene & 1.66 & 1.98 & 2.91 & 3.68 \\
o-Xylene & 2.09 & 2.47 & 3.08 & 4.07 \\
m-Xylene & 1.58 & 2.12 & 2.87 & \\
p-Xylene & 1.63 & 2.39 & 2.92 & \\
\hline
\end{tabular}

Table A.X contains the partition coefficients, $K_{p}$, of benzene and its $C_{1}$ and $C_{2}$ alkyl substituted derivatives at several temperatures.

Table A.X. Partition coefficients, $K_{p}$, at several temperatures

\begin{tabular}{lcccc}
\hline & $298.2 \mathrm{~K}$ & $313.2 \mathrm{~K}$ & $328.2 \mathrm{~K}$ & $343.2 \mathrm{~K}$ \\
\hline Benzene & 4.23 & 2.61 & 1.76 & 1.33 \\
Toluene & 4.10 & 2.20 & 1.45 & 0.97 \\
Ethylbenzene & 3.24 & 1.80 & 1.34 & 0.93 \\
o-Xylene & 5.69 & 3.14 & 1.95 & 1.38 \\
m-Xylene & 3.53 & 2.18 & 1.49 & \\
p-Xylene & 3.46 & 2.34 & 1.45 & \\
\hline
\end{tabular}


Table A.XI gives the Henry's law constants, $k$, of benzene and its $C_{1}$ and $C_{2}$ alkyl substituted derivatives at several temperatures.

Table A.XI. Henry's law constant, $\mathrm{k} /\left(10^{7} \mathrm{~Pa}\right)$, at several temperatures

\begin{tabular}{lccrl}
\hline & $298.2 \mathrm{~K}$ & $313.2 \mathrm{~K}$ & $328.2 \mathrm{~K}$ & $343.2 \mathrm{~K}$ \\
\hline Benzene & 3.25 & 5.53 & 8.60 & 12.27 \\
Toluene & 3.36 & 6.63 & 10.76 & 16.75 \\
Ethylbenzene & 4.24 & 8.11 & 11.52 & 18.05 \\
o-Xylene & 2.39 & 4.63 & 7.89 & 11.73 \\
m-Xylene & 3.89 & 6.70 & 10.32 & \\
p-Xylene & 3.97 & 6.29 & 10.60 & \\
\hline
\end{tabular}

Table A.XII contains the oil/aqueous Nernst distribution constants, $K_{d}$, of benzene and its $C_{1}$ and $C_{2}$ alkyl substituted derivatives at several temperatures.

Table A.XII. Nernst distribution constants, $K_{d}(=[0 i 1] /[$ aqueous $])$, at several temperatures

\begin{tabular}{lrrrr}
\hline & $298.2 \mathrm{~K}$ & $313.2 \mathrm{~K}$ & $328.2 \mathrm{~K}$ & $343.2 \mathrm{~K}$ \\
\hline Benzene & 176.3 & 166.0 & 158.6 & 134.1 \\
Toluene & 477.2 & 549.9 & 485.4 & 421.2 \\
Ethylbenzene & 1408.3 & 1284.8 & 939.0 & 872.3 \\
O-Xylene & 1092.4 & 1012.2 & 848.2 & 668.4 \\
m-Xylene & 1515.6 & 1118.2 & 823.9 & \\
p-Xylene & 1443.0 & 1114.3 & 870.4 & \\
\hline
\end{tabular}

Since at constant temperature the chemical potential of a solute is the same in all of its saturated solutions, the activity coefficients for the substance in two solutions with different solubilities obey the relationship

$$
\gamma_{1} / \gamma_{2}=S_{2} / S_{1}
$$


If for one solution the solvent is water, then for a solute with limited solubility

$$
\gamma_{i}=S_{a q} / S_{i} .
$$

The assumption implicit in Equation 7 is that the solute activity coefficient is 1.00 in the saturated aqueous solution. The validity of this assumption increases as $S^{0} \rightarrow 0$. Since the mole fraction solubilities of benzene, toluene, ethylbenzene, $0_{-}, \mathrm{m}-$, and $\mathrm{p}$-xylene are of the order of $10^{-4}$ Equation 7 can be used to compute the activity coefficients from the solubility values obtained in this study. Plots of $\ln (\gamma)$ or $\ln (S)$, for benzene or toluene, as a function of ionic strength are linear with correlation coefficients of 0.998. These plots yield salting out coefficients, $d \ln (S) / d \mu$, of -0.423 and -0.464 for benzene and toluene respectively.

\section{A.4. Discussion}

In Figure A.2 we have plotted the solubilities for benzene and toluene from our earlier work (2) and the solubilities for the $C_{2}$ substituted benzenes from this study as a function of the molar volumes listed in Table A.XIII. The linear correlation coefficients of the Figure $A .2$ plots at ionic strength, $\mu=$ 0 to 5 are $0.999,0.998,1.000,0.997,0.997$ and 0.992 , respectively. While such plots are popular they suffer from the objection that while molar volumes computed from solute densities and molecular weights may be proportional to the effective volume of solute molecules in the pure solutes, they are not necessarily true indicators of the effective volumes of solute molecules in other solvents. 


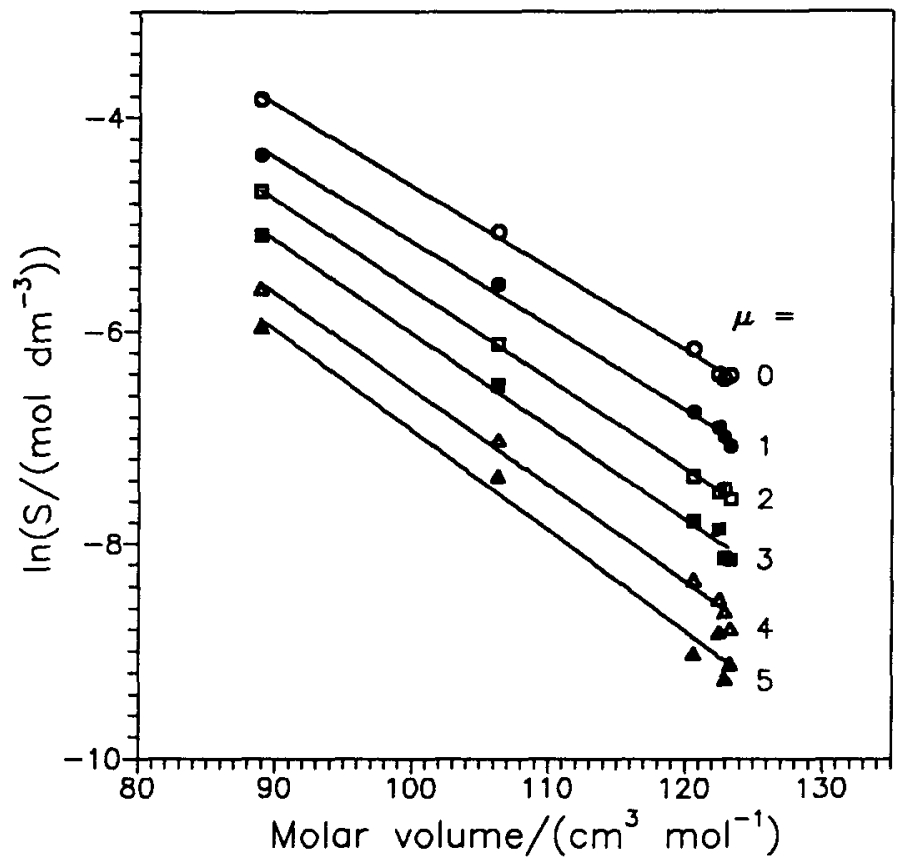

Figure A.2. Natural logarithm of the aqueous solubility of benzene, methylbenzene, ethylbenzene, 1,2-, 1,3- and 1,4-dimethylbenzene as a function of molar volume and ionic strength, $\mu$, at $298.2 \mathrm{~K}$.

More recently the use of molar volume has been replaced by molecular surface area (MSA), originally suggested by Langmuir in connection with solution free energies, as a more appropriate variable. While molecular surface areas are theoretically more appealing they are not easily computed. Figure A.3 is a plot of solubility values from this study as a function of MSA. The MSA values used, Table A.XIII, are those of Amidon et al. Linear correlation coefficients for the Figure A.3 plots for ionic strength, $\mu=0$ to 5.00 are $0.999,0.998,0.998,0.998,0.998$ and 0.990 , respectively. 
Table A.XIII. Molar volumes and molecular surface areas

\begin{tabular}{|c|c|c|}
\hline Compound & $\begin{array}{l}\text { Molar volume/ } \\
\left(\mathrm{cm}^{3} \mathrm{~mol}^{-1}\right)\end{array}$ & $\begin{array}{l}\text { Molecular surface area/ } \\
\qquad\left(10^{-16} \mathrm{~cm}^{2}\right)\end{array}$ \\
\hline Benzene & 88.91 & 255.7 \\
\hline $\begin{array}{l}\text { Methyl - } \\
\text { benzene } \\
\text { Ethyl - }\end{array}$ & 106.3 & 286.5 \\
\hline benzene & 122.5 & 315.6 \\
\hline $\begin{array}{l}\text { benzene } \\
\text { 1,3-Dimethy1- }\end{array}$ & 120.6 & 309.7 \\
\hline $\begin{array}{l}\text { benzene } \\
1,4 \text {-Dimethy } 1 \text { - }\end{array}$ & 122.9 & 317.6 \\
\hline benzene & 123.3 & 317.6 \\
\hline
\end{tabular}

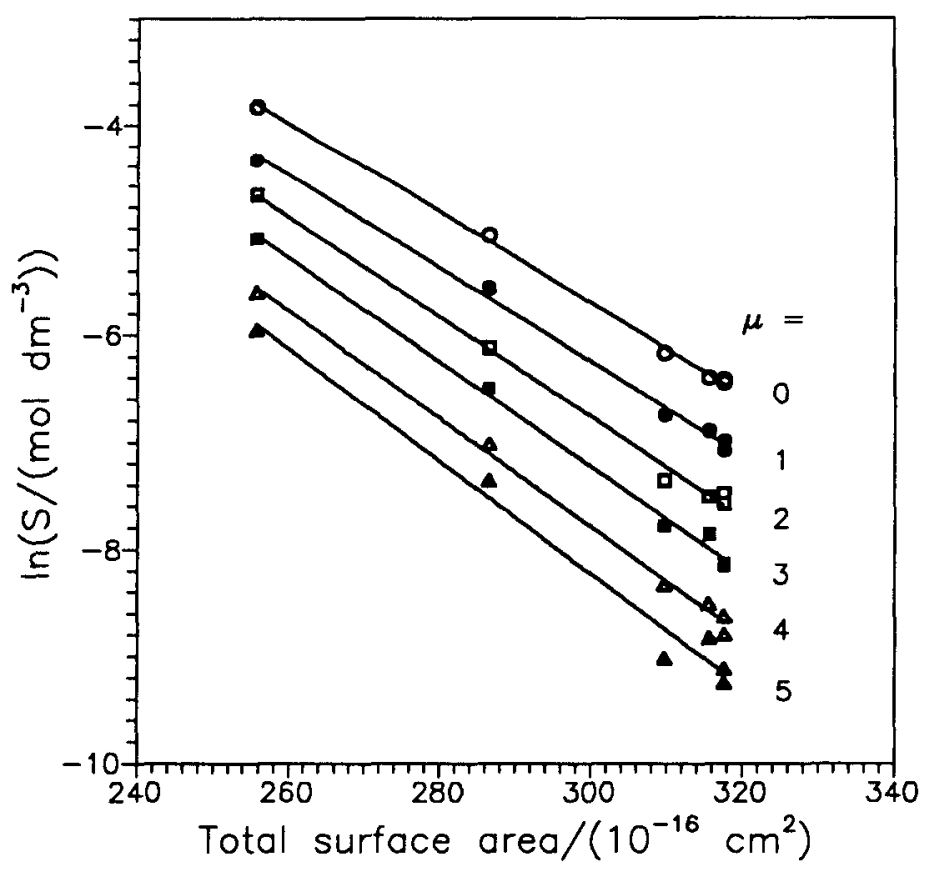

Figure A.3. Natural logarithm of the aqueous solubility of benzene, methylbenzene, ethylbenzene, 1,2-, 1,3- and 1,4-dimethylbenzene as a function of molecular surface area and ionic strength, $\mu$, at $298.2 \mathrm{~K}$.

Benzene and its $C_{1}$ and $C_{2}$ substituted analogs are all liquids at room temperature. With the exception of ethytbenzene these substances may be viewed as rigid molecules in which a benzene hydrogen has been replaced by a methyl group. To a first approximation, the molecular volumes (MV) or molecular 
surface areas (MSA) of such a series can be represented by a sum of group contributions

$$
\Sigma G C=B-n H_{B}+n\left(M-H_{M}\right)
$$

where $n$ is the number of methyl groups, $B$ is the benzene value and $M$ the methane values for the appropriate property and $H_{B}$ and $H_{M}$ are the corrections to the value corresponding to the removal of one hydrogen atom from benzene and methane, respectively. Equation 8 may be simplified to

$$
\Sigma G C=B+n S
$$

where $S=M-H_{B}-H_{M}$. Figure $A .4$ is a plot of the natural logarithms of the aqueous solubilities of benzene, toluene and 1,2-, 1,3-, and 1,4-dimethylbenzene as a function of their $\Sigma G C$ values as computed from Equation 8 in which $B$ and $S$ have been assigned arbitrary values of one and for which $n=0,1$, and 2 for benzene, methylbenzene and the dimethylbenzenes, respectively. The linear correlation coefficients of the aqueous solubility data plotted in this fashion are for $\mu=0$ to $5,0.995,0.994,0.998,0.994,0.992$ and 0.997 , respectively. Since such plots find their greatest use in estimating solubilities, we feel that when conditions and available data justify it, a simple approach like Equation 9 gives a useful first approximation.

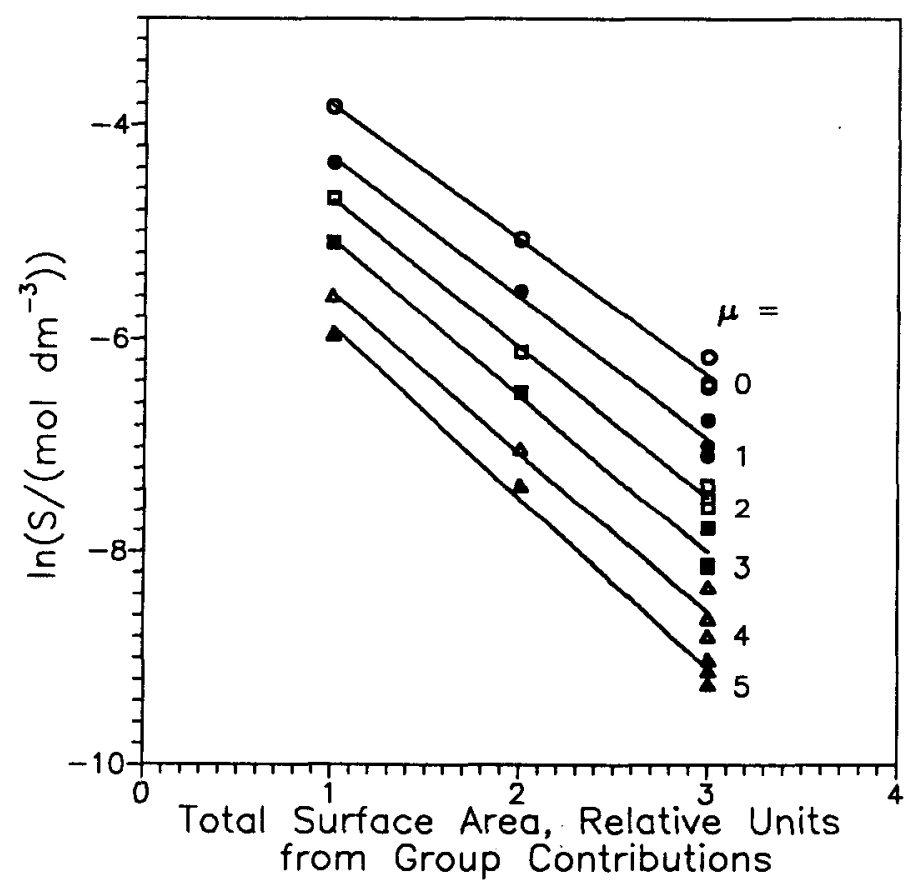

Figure A.4. Natural logarithm of the aqueous solubility of benzene, methylbenzene, 1,2-, 1,3- and 1,4-dimethylbenzene as a function of group contributions and ionic strength at $298.2 \mathrm{~K}$. For the aqueous 1 ine $(\mu=0):$ In $\left(S, \mathrm{~mol} \mathrm{dm}^{-3}\right)$ $=-1.26 \Sigma G C-2.56$ where $\Sigma G C=1,2$, and 3 for benzene, methybenzene, and the dimethylbenzenes, respectively. 
Figure A.5 is a graph of the natural logarithm of the aqueous solubility, $\ln (S)$, as a function of reciprocal temperature $(1 / K)$ for the compounds studied.

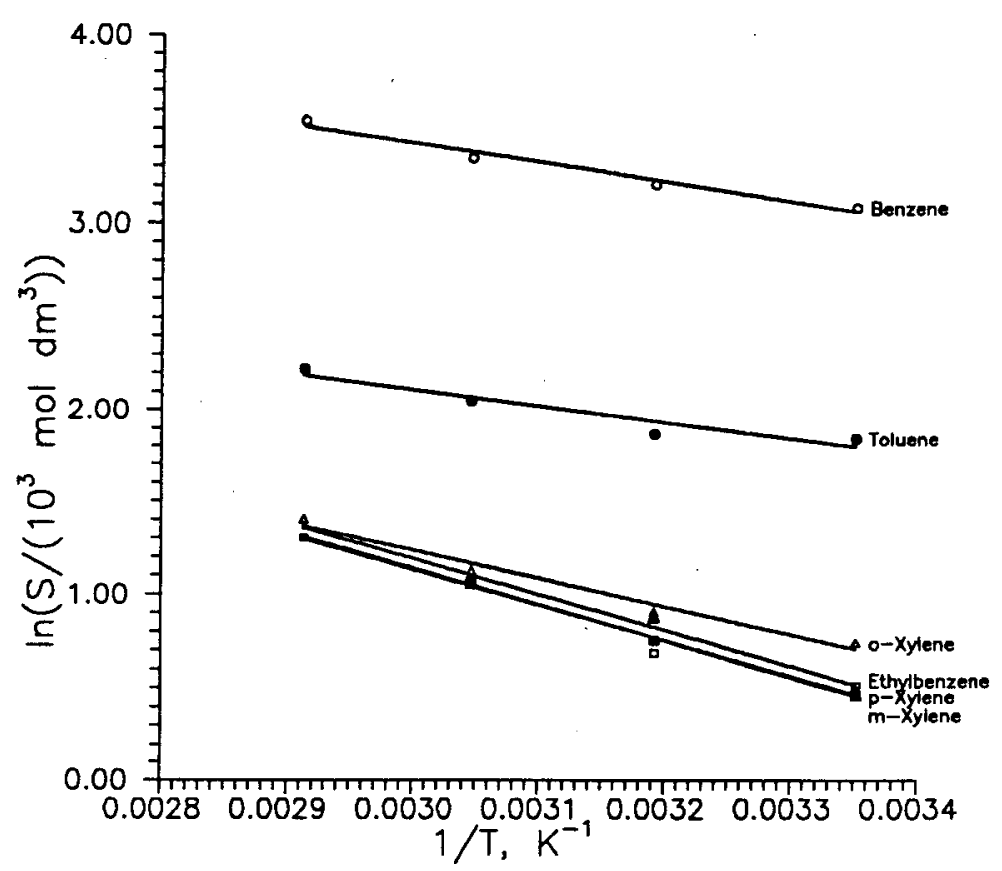

Figure A.5. Plot of $\ln (S)$ as a function of $1 / T$ for benzene and it $C_{1}$ and $C_{2}$ alkyl substituted derivatives. 


\section{A.5. Selected Bibliography}

Andrew, L.J.; Keefer, R.M. J. Am. Chem. Soc. 1949, 71, 3644.

Arnold, D.S.; Plank, C.A.; Erickson, E.E.; Pike, F.P. Chem. Eng. Data Ser. $1958,3,253$.

Bohon, R.L.; Clausen, W.F. J. Am. Chem. Soc. 1951, 73, 1571.

Butler, J.A.V. J. Phys. Chem. 1929, 33, 1015.

Debye, P.; McAulay, J. Physik. Z. 1925, 26, 22.

Debye, P. Z. physik. Chem. 1927, 130, 56.

Green, W.J.; Frank, H.S. J. Solut. Chem. 1979, 8, 187.

Hayashi, H.; Sasaki, T. Bull. Chem. Soc. Jpn. 1956, 29, 857.

Keeley, D.F.; Meriwether, J.R., Rev. Sci. Instrum. 1986, 75(7), 1434.

Keeley, D.F.; Hoffpauir, M.A.; Meriwether, J.R., Anal. Chem. 1986, 58, 1258.

Keeley, D.F.; Hoffpauir, M.A.; Meriwether, J.R., J. Chem. Eng. Data 1988, $\underline{33}, 87$.

Keeley, D.F.; Hoffpauir, M.A.; Meriwether, J.R., J. Chem. Eng. Data 1991, $36,456$.

Klevens, H.B. J. Phys. Colloid. Chem. 1950, 54, 283.

"Lange's Handbook of Chemistry", 12th ed.; Dean J.A., Ed.; McGraw-Hi1l: New York, 1979; pp. 10-28.

Long, F.A.; McDevit, W.F. Chem. Revs. 1952, 51, 119.

Mackay, D.; Shiu, W.Y. Can. J. Chem. Eng. 1975, 53, 239.

Mackay, D.; Shiu, W.Y.; Sutherland, R.P. Environ. Sci. Tech nol. 1979, 13, 333.

Massaldi, H.A.; King, C.J. J. Chem. Enq. Data 1973, 18(4), 393.

May, W.E.; Wasik, S.P.; Miller, M.M.; Tewari, Y.B.; Brown- Thomas, J.M.; Goldberg, R.N. J. Chem. Eng. Data 1983, 28, 197.

McAul iffe, C. J. Phys. Chem. 1966, 70, 1267.

Polak, J.; Lu, B.C.Y. Can. J. Chem. 1973, 51, 4018.

Price, L.C. Ph.D. Dissertation, University of California, Riverside, Calif., 1973.

Sanemasa, I.; Araki, M.; Deguchi, T.; Nagai, H. Bull. Chem. Soc. Jpn. 1982, $\underline{55}, 1054$.

Schwarz, F.P. Anal. Chem. 1980, 52, 10.

Sutton, C.; Calder, J.A. J. Chem. Eng. Data 1975, 20, 320.

Taha, A.A.; Grisby, R.D.; Johnson, J.R.; Christian, S.D.; Affsprung, H.E. J. Chem. Educ. 1966, 43, 432.

Tsibulskii, V.V.; Tsibulskaya, I.A.; Yaglitskaya, N.N. Zh. Analit. Khim. $1979, \underline{34}, 1364$.

Worley, J.D. Can. J. Chem. 1967, 45, 2465. 
20

$$
20
$$




\section{B. DOE Design Well Sampling}

\section{B.1. Time Frame}

For completeness this section of the final report cover the time frame $6 / 17 / 88$ to $9 / 10 / 92$. During the indicated time frame, USL staff members sampled the Pleasant Bayou Well forty-four (44) times.

\section{B.2. Sampling Procedure}

In addition to the light aliphatic alkanes, e.g. methane - $\mathrm{CH}_{4}$, ethane $\mathrm{C}_{2} \mathrm{H}_{6}$, etc., normally associated with natural gas, all Gulf Coast geopressured brines studied to date, contain a large number, $>90$, of aromatic hydrocarbons that range in complexity from benzene to trialkyl substituted anthracenes.

These aromatic hydrocarbons are partially exsolved from the geopressured brine along with the light aliphatic alkanes as the pressure of the brine is reduced during brine production. We have named the aromatic hydrocarbon mixture 'cryocondensate' since they can be effectively removed from the exsolved gas stream by cryogenic techniques. A small portion of the total exsolved aromatic mixture condenses out in the gas cooler at most geopressured well sites and is simply referred to by site personnel as 'condensate'.

To precisely quantify the total amount of cryocondensate present in the formation brine would be difficult and is unnecessary. The difficulty in exact quantification is due to the complexity of the mixture. It consists of over 90 compounds, the vast majority of which have not been characterized. Indeed, even if complete characterization were contemplated, some of the compounds in the mixture may be unknown and obtaining samples to use in standardization would be difficult, time consuming and very expensive. Fortunately the vast majority of the cryocondensate consists of a few common and therefore readily obtainable compounds. Table B.I lists the amounts, based upon gas chromatographic area percent, of the most abundant aromatic compounds in the cryocondensate recovered from the gas exsolved from a typical geopressured well.

Quantification of the cryocondensate present in the formation brine requires determining the amount present in the exsolved gas and the amount remaining unexsolved in the source brine. 
Table B.I. Most abundant aromatic hydrocarbons obtained from a typical sample of cryocondensate recovered from the exsolved gas from the Gladys McCall geopressured well located in Cameron Parish, Louisiana (5/4/87).

\begin{tabular}{ccc}
\hline & Compound & Area Percent \\
Benzene & 51.97 \\
Toluene & 17.92 \\
Ethylbenzene & 2.25 \\
p-Xylene & 0.75 \\
m-Xylene & 3.84 \\
0-Xylene & 3.04 \\
Percent of total cryocondensate & \\
\hline
\end{tabular}

\section{B.2.a. Cryocondensate from Exsolved Gas}

The cryocondensate carried from the brine with the light aliphatic alkanes is quantitatively measured in the following manner. Gas from the top of the brine-gas separator is passed through a series of glass traps which are immersed in dry-ice/acetone baths. Those hydrocarbons with partial pressures greater than their vapor pressures at $-78^{\circ} \mathrm{C}$ are removed by this process. The volume of gas sampled is measured by means of a series connected wet-test meter, as shown in Fig. B.1.

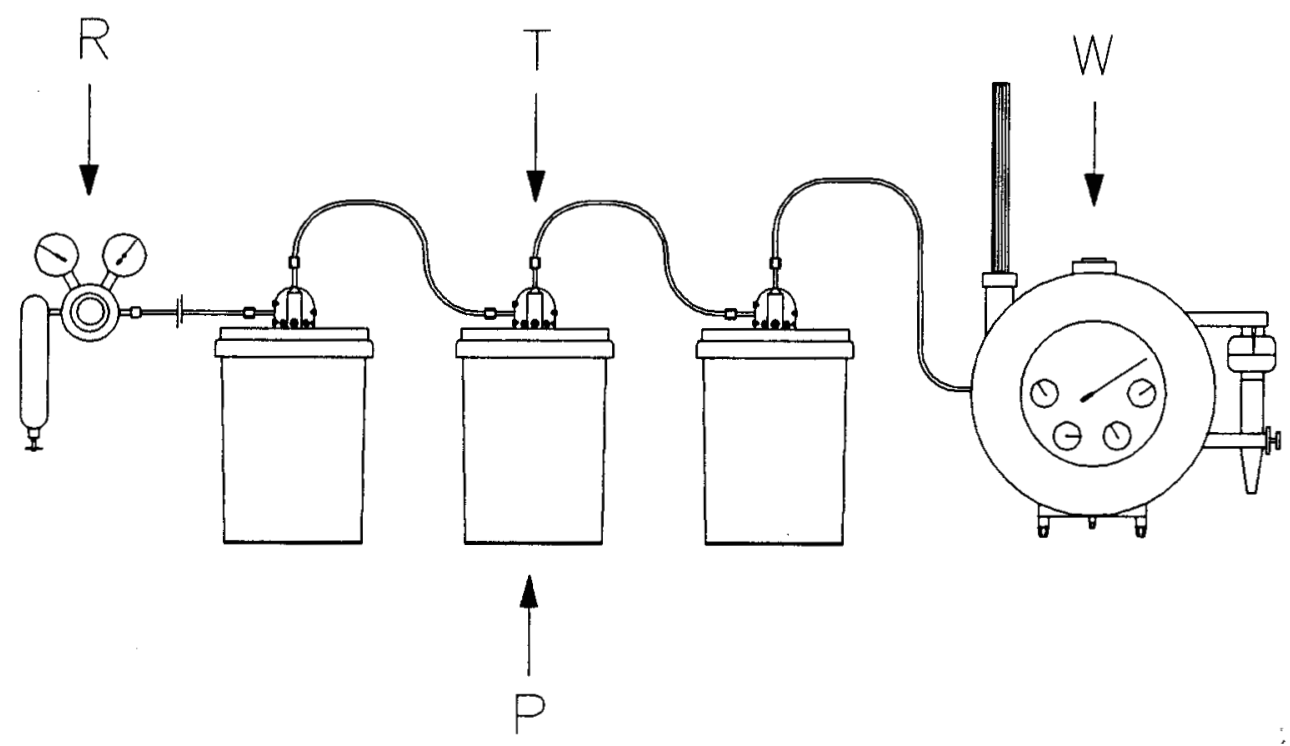

Figure B.1. Experimental set-up for collecting "cryocondensate" from DOE geopressured wells. $R=$ two-stage gas regulator with condensation trap, $T=$ Pyrex ${ }^{\circledR}$ lass traps, $P=$ polypropylene Dewar flasks, $W=$ wet-test meter. 
The cryocondensate thus recovered is thawed and manually poured from the traps into a semi-micro buret for measurement. Residual cryocondensate is washed from the traps with hexane and is collected in a volumetric flask (trap wash) for later quantification by gas chromatography.

\section{B.2.b. Residual Cryocondensate from Brine:}

Since only a portion of each of the aromatic hydrocarbons which comprise the cryocondensate is exsolved with the gas, the residual aromatic compounds in the brine must be determined. This is accomplished by first collecting a sample of chilled brine from the same separator from which the sampled gas came. The residual aromatic hydrocarbons in the brine are determined by extracting a portion of the brine, usually one liter, with a small volume of hexane, generally $25 \mathrm{~cm}^{3}$. The hexane extract (brine extract) is then analyzed, by gas chromatography, to determine the concentration of the extracted aromatics. 

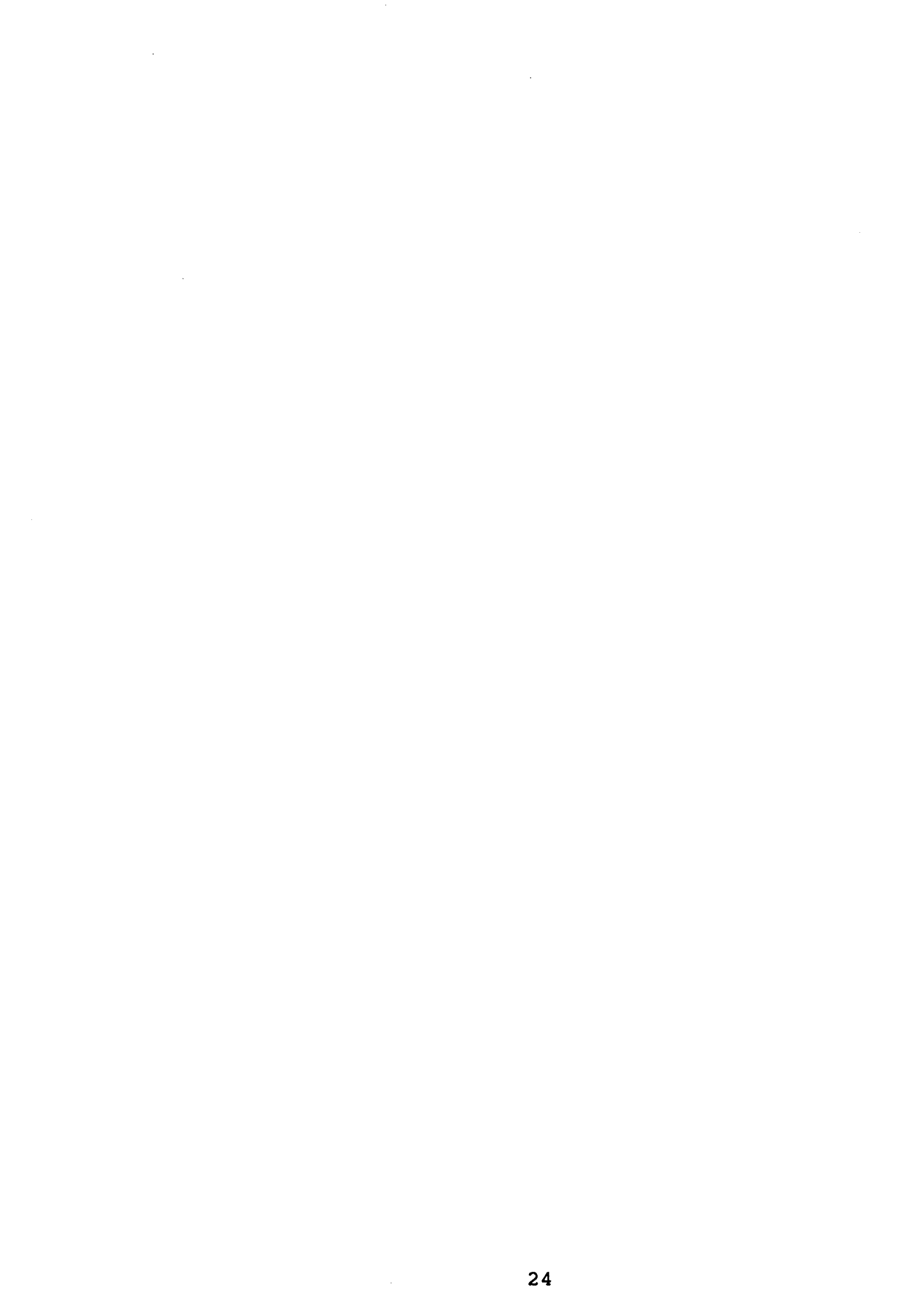


\section{Analysis of Well Samples}

\section{C.1. Time Frame}

For completeness this section of the final report cover the time frame $6 / 17 / 88$ to $9 / 10 / 92$. During the indicated time frame, USL staff members analyzed samples from the Pleasant Bayou Well.

\section{C.2. Analysis Procedure}

Analysis of the cryocondensate, trap wash solution and brine extract solution is done by gas chromatographic analysis. The analysis is done relative to a series of laboratory prepared standards. These standards contain a maximum of 40 microliters $\left(0.040 \mathrm{~cm}^{3}\right)$ of the dominant aromatic components of the cryocondensate dissolved in $25 \mathrm{~cm}^{3}$ of hexane. One microliter $\left(0.001 \mathrm{~cm}^{3}\right)$ of each standard solution, which contains a maximum of 0.002 microliters $\left(0.000002 \mathrm{~cm}^{3}\right)$ of the aromatic solute, is used per determination. One microliter of the trap wash solution and the brine extract solution are used per determination. The gas chromatographic analysis employs a flame ionization detector which consumes the injected sample and converts it ultimately to carbon dioxide and water.

The concentration of cryocondensate in the source brine is computed from the volume of cryocondensate recovered, the concentration of dominant aromatic in the trap wash solution and the concentration of dominant aromatics in the brine extract solution by means of a USL written computer program called "CRYOHYD.BAS" (Appendix A).

\section{C.3. Results}

The concentration of "cryocondensate" expressed as $\mu \mathrm{L} /(\mathrm{L}$ of brine) as a function of cumulative brine volume expressed as kbbl (Mbbl in oil-field terms) for the forty-four samples from $6 / 17 / 88$ to $9 / 10 / 92$ are shown in Figure C. 1 . 


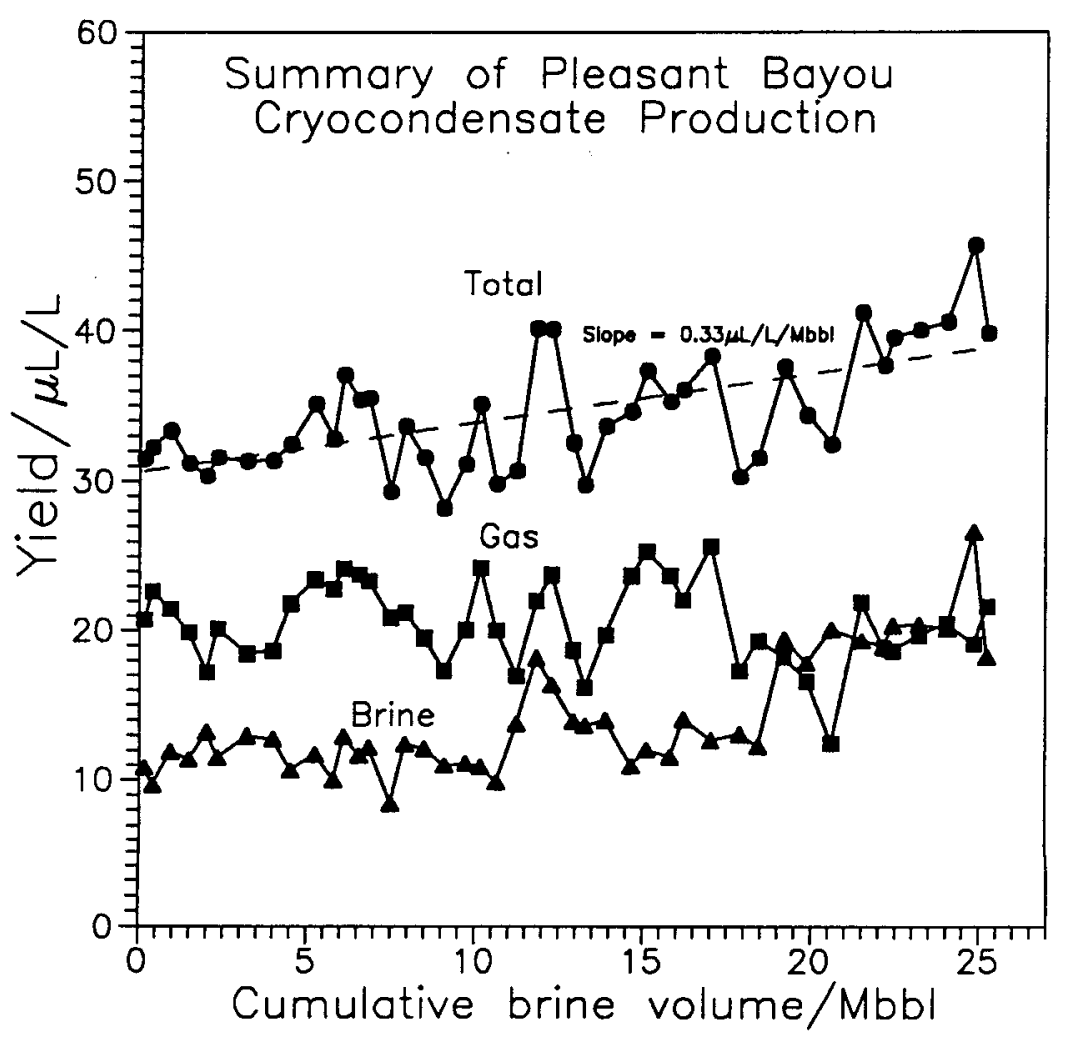

Figure C.1. Concentration of "cryocondensate", in $\mu L /(L$ of brine $)$, as a function of cumulative brine volume, in kbbl (Mbbl), from $6 / 17 / 88$ to $9 / 10 / 92$, for the Pleasant Bayou Well, Brazoria County, Texas. 


\section{Review of Theoretical Models of Geopressured Reservoir Hydrocarbons}

\section{D.1. Review of scientific literature}

Period Covered The scientific literature was electronically surveyed for references to geothermal/geopressured reservoir/formation hydrocarbons. The time frame covered was 1968 through May 11, 1993.

\section{D.2. Search strategy}

Using the search strategy

(GEOTHER? OR GEOPRESS?) AND (FORMATION? OR RESERVOIR?) AND HYDROCARBON?

where ? indicates that all words containing the stem preceding the ? were searched. Thirty-two (32) references were located which satisfied the search strategy. The references, in reverse chronological order, with their abstracts are listed below. The language of the article is given in parentheses.

\section{D.3. References and abstracts}

1. Porshnev, N.V.; Mukhim, L.M.; Bonderev, V.B.; Safonova, E.N.; Kalinichenko, V.I., "Aromatic fractions of hydrothermal manifestations in petroleum. Polycyclic aromatic hydrocarbons.", Dokl. Akad. Nauk SSSR, 1991, 320(2), 450. (Russian)

Abstract: Experiments modeling geothermal conditions of formation and accumulation of polycyclic aromatic hydrocarbons (pyrolysis of $\mathrm{CH}_{4} / \mathrm{H}_{2} \mathrm{O}$ at $1000-1100^{\circ}$ ) indicate that synthesis may play an important role in the chemistry of geothermal processes. Characteristic stages of such processes are the formation of $C$ association and coking.

2. Grechishnikov, N.P., "Geothermal processes of petroleum and gas formation.", Dokl. Akad. Nauk SSSR, 1991, 319(2), 427. (Russian)

Abstract: A review, with 15 references, of geothermal processes of petroleum and natural gas formation. During the sedimentary stage, conductive heat transfer does not secure the necessary thermobaric conditions for the formation of source rock in terms of their practical meaning. Hydrocarbon reservoirs of industrial meaning are formed during the postsedimentation (inversion) stage as a result of convection heat 
transfer and carrying out hydrocarbon fluids from zones of their formation to zones of less rigid temperature conditions.

3. Kecheruk, E.V.; Ozernyi, O.M., "Relation between the phase composition of hydrocarbons in the Black Sea-Crimean petroleum-natural gas region and geothermobarometric conditions.", Geol. Neffi Gaza, 1990, (2), 19. (Russian)

\begin{abstract}
The phase composition of hydrocarbons in the Crimean petroleum-natural gas area was studied. Six zones of hydrocarbon reservoirs of various phase composition were identified depending on thermobaric conditions. The occurrence of petroleum in the Black Sea-Crimean area is limited to horizons with pressure $30 \mathrm{MPa}$ and temperature $104^{\circ}$, but the maximum values for natural gas are $31 \mathrm{MPa}$ and $127^{\circ}$, respectively. Commercial accumulations of hydrocarbons are concentrated only in 3 zones; only one of them, which is characterized by abnormally high reservoir pressures, contains major pools.
\end{abstract}

4. Porshnev, N.N.; Bonderev, V.B., "Formation of hydrocarbons under natural hydrothermal conditions.", Neftekhimiya, 1989, 29(6), 731. (Russian)

Abstract: A review with 40 references of the role of hydrothermal systems in the generation of petroleum and natural gas hydrocarbons. The formation of $\mathrm{C}_{2-11}$ hydrocarbons is controlled by thermal reactions at $1000 \pm 200$ and $300 \pm 100^{\circ}$.

5. Nazarenko, V.S., "Effect of geothermal and paleogeothermal conditions on the distribution of hydrocarbons in the Paleozoic formations of the Rostov region.", Izv. Vyssh. Uchebn. Zaved., Geol. Razved., 1989, (5), 137. (Russian)

Abstract: The temperature gradient of Paleozoic sediments of the Rostov region, USSR, is 2.46-3.48\%/100 $\mathrm{m}$, and the temperature of petroleum reservoirs in this region is slightly higher than that of natural gas reservoirs. The current geological temperatures in this region are substantially lower than maximum paleotemperatures. The maximum paleotemperatures of stratal waters were $80-100^{\circ}$ higher than those of rocks. There is a close correlation among the maximum paleotemperatures of rocks and waters and coal metamorphism.

6. Porshnev, N.V.; Bondarev, V.B., " $C_{1}-C_{11}$ hydrocarbons in high-temperature geotherms. Quantitative variations and formation paths.", Dokl. Akad. Nauk SSSR, 1989, 306(3), 708. (Russian) 
Abstract: A review with 15 references on the nature, quantity, and distribution of hydrocarbons formed from deep and nearsurface high-temperature geothermal systems; mechanisms of hydrocarbon formation are also discussed. The transformation of organic matter and the formation of $c_{1-11}$ hydrocarbons under high-temperature geohydrothermal conditions is attributed to pyrolysis at $1000 \pm 200^{\circ}$ and thermolysis and catalytic reactions at $300 \pm 100^{\circ}$.

7. Marty, B.; Criaud, A.; Fouillac, C., "Low-enthalpy geothermal fluids from the Paris Sedimentary Basin. 1. Characteristics and origin of gases.", Geothermics, 1988, 17(4), 619. (English)

Abstract: Fifty-seven wells tapping low-enthalpy geothermal waters in the Dogger limestone reservoir of the Paris Basin were sampled and analyzed for their gas composition. $\mathrm{CH}_{4} / \mathrm{C}_{2} \mathrm{H}_{6}$ ratios indicate that the hydrocarbons originate through both biogenesis and thermogenesis. Relatively high and variable $\mathrm{H}_{2}$ concentrations are likely to result from fluid interaction with geothermal installations. Regional trends among main species $\left(\mathrm{N}_{2}, \mathrm{CO}_{2}, \mathrm{CH}_{4}\right)$ reflect large-scale heterogeneities which were previously revealed by the geochemistry of the fluids (Criaud, A. et al., 1986). Northern sites are generally $\mathrm{N}_{2}$-rich and southern sites $\mathrm{CH}_{4}$-rich; this characteristic may be 7 inked to the occurrence of oil-bearing zones in the south. $\mathrm{N}_{2}, \mathrm{Ar}$, and He absolute contents show clear positive correlations. In particular, $\mathrm{N}_{2}-\mathrm{Ar}$ trends are best explained by the occurrence of a paleocomponent, likely to be evolved seawater. He model ages are consistent with the geologic age of the host formation but contradict the hydrologic ages. Assuming an exotic flux of He into the aquifer this discrepancy may be overcome, but its computed rate apparently exceeds the current estimates for the continental degassing flux.

8. Belkin, H.E.; Cavarretta, G.; De Vino, B.; Tecce, F., "Hydrothermal phlogopite and anhydrite from the SH2 well, Sabatini volcanic district, Latium, Italy: Fluid inclusions and mineral chemistry., Am. Mineral., 1988, 73(7-8), 775. (English)

Abstract: Samples from an exploratory hole drilled to access the geothermal potential of the area north of Bracciano Lake, Lathium, Italy, are from a thermometamorphic-metasomatic zone (1140-2498.7 m) and contain hydrothermal anhydrite \pm phlogopite (+ calcite \pm pyrite) and other authigenic volatile-rich phases. Microthermometry of primary and secondary 2-phase 
[vapor (V) + liquid (L)] and multiphase [V + L + crystals] liquid-rich inclusions in anhydrite yields pressure-correlation temperatures of homoginazation (trapping temperatures) of 144-304 ${ }^{\circ}$, generally coincident with measured in-hole temperatures. The fluids have a variable salinity of $0.5-14.0$ weight percent $\mathrm{NaCl}$ equivalent and also contain $\mathrm{Ca}^{2+}$. Rare liquid $\mathrm{CO}_{2}$-bearing aqueous inclusions were verified by laser Raman spectroscopy. Also, rare liquid hydrocarbons were observed. Clatherates were observed upon freezing, and crushing studies show noncondensable gas at $P>1$ atm in some inclusions. Euhedral to subhedral phlogopite crystals $(-0.5$ to $\sim 2 \mathrm{~mm})$ commonly are zoned and contain solid inclusions of anhydrite and apatite and 2-phase $[V+L]$ and multiphase $[V+L+$ crystals] fluid inclusions. Microthermometry of primary 2-phase inclusions yields pressure-correlation temperatures of homogenization (trapping temperatures) of $178-298^{\circ}$ and are also generally coincident with in-hole measured temperatures. Freezing studies show a variable fluid salinity $(0.2-7.8$ weight percent $\mathrm{NaCl}$ equivalent); the fluid contains $\mathrm{Ca}^{2+}$. If the current hydrologic regime existed during anhydrite and phlogopite formation, the pressure of formation was -148 to $\sim 220$ bars for phlogopite $(1600-\sim 2500 \mathrm{~m})$ and -120 to -220 bars for anhydrite $(1300-2500 \mathrm{~m})$. Hence the phlogopite and other authigenic phases crystallized from a low pressuretemperature, volatile-rich, generally dilute geothermal solution. The variation of fluid-inclusion salinities, the phlogopite zoning, and the chemical variation of the anhydrite and phlogopite suggest that different fluids and/or episodic conditions were operative in this geothermal system.

9. Strubhar, M.K., "Limited entry method for inducing simultaneous multiple fracture in deviated wellbores.", Brit UK Pat. Appl..2 (GB 2197364 Al 18 May 1988 (English)

Abstract: A hydraulic fracturing process induces simultaneous multiple vertical fractures in a deviated wellbore in a subterranean formation for the removal of resources, e.g., ores, geothermal heat, coal, oil shale, or especially hydrocarbonaceous fluids. The process results in increased recovery of hydrocarbonaceous fluids when combined with steam flooding or solvent or surfactant stimulation processes. The wellbore is selectively perforated with holes sufficiently apart that multiple vertical fractures are produced. This occurs when the fracturing fluid rate through the limited holes causes a pressure drop across the hole sufficient to divert the fluid 
essentially through all of the holes. The angle of incidence or deviation is $10-90^{\circ}$.

10. Neruchev, S.G.; Mukhin, V.V.; Rogozina, E.A.; Chervyakov, I.B., "Anomalous high pressure as an indicator of the generation of hydrocarbons.", Sov. Geol., 1987, $(10), 33$. (Russian)

Abstract: The possibility of sudden release of hydrocarboncontaining fluids from closed pores in clay formations is explored. Such sudden, nearly explosive releases are theoretically possible when a tectonic disturbance produces a drop in overall stratal pressure. The release can generate pools of liquid and gaseous hydrocarbons, which can migrate. A geologic survey of a region can pin-point lines or zones of such sudden fluid releases. This is helpful in petroleum and natural gas prospecting.

11. Adams, M.C.; Ahn, J.H.; Bentley, H.; Moore, J.N.; Veggeberg, S., "Derivatized hydrocarbons as geothermal tracers", Irans. = Geotherm. Resour. Counc., 1986, 10(Geotherm. Energy, 415.

Abstract: The thermal stability of trifluoromethyl-, sulfonate-, Me-, $\mathrm{F}-$, and $\mathrm{CO}_{2} \mathrm{H}$-substituted aromatic hydrocarbons was evaluated at $\geq 250^{\circ}$, for use as geothermal tracers to track fluid movement and chemical changes in reinjected brines. Significant decay of the compounds occurred at $200-250^{\circ}$, and the degradation was time-dependent; fluorinated compounds were the most stable at $<250^{\circ}$.

12. Ugrekhelidze, G.P.; Chukhir, M.G.; Parnas, Ya.M., "Study of sulfate and hydrocarbonate equilibria in formation and geothermal waters of Azerbaidzhan.", Ispol'z Vozobnovlyaemykh Istochnikov Energii i Okhrana Okruzh. Sredy v Energ. M., 1987, From: Ref. Zh. Khim.. Abstr. No. 8I366, 50. (Russian)

Abstract: No abstract.

13. Prokof'ev, V.Yu.; Naumov, V.B., "Geochemistry of ore-forming solutions of the Zyryanovskoe pyrite-polymetallic ore deposit, Rudnyi Altai", Geokhimiya, 1987, (3), 375. (Russian)

Abstract: A study of fluid inclusions in calcite and sphalerite of ores and wall rocks showed that the ore-forming solutions for the Zyryanoskoe deposit contained chlorides of $\mathrm{Mg}$, $\mathrm{Na}$, and $\mathrm{K}$ at a concentration of 8-18 weight percent equivalent 
$\mathrm{NaCl}$, a significant quantity of $\mathrm{CO}_{2}$ and $\mathrm{CH}_{4}(5.9$ and 1.4 $\mathrm{mol} / \mathrm{kg}$ of solution, respectively), and complex hydrocarbons; these solutions were at 1.6-3.1 kbar and 145-360 $0^{\circ}$ The fugacity, calculated based on the $\mathrm{CO}_{2}-\mathrm{CH}_{4}$ equilibrium decreased from $10^{-31}$ (at $360^{\circ}$ ) to $10^{-47}$ (at $170^{\circ}$ ). The geological and mineralogical data for the area shows that parameters of the oreforming solution (temperature, pressure, concentration of dissolved constituents) decrease both in space (from the center to periphery) and in time (from early. to late mineral association) in the deposit. The distribution of these parameters shows conformity to the geologic structure in the country rocks.

14. Kaiser, W.R., "Predicting reservoir quality and diagenetic history in the Frio Formation (01 igocene) of Texas.", AAPG Mem., 1984, 37(Clastic Diagenesis), 195. (English)

\begin{abstract}
Diagenesis in the FRio Formation occurs as a function of temperature, $\mathrm{pH}$, activity, and pressure in the transition zone between the hydropressured and geopressured interval at low temperatures. Activity indexes favoring chlorite and ferroan calcite [68859-12-1] stability and large Ca-Na ratios are the best indicators of reservoir quality in deep Frio sandstone reservoirs. Predictions about Frio diagenesis based on equilibrium thermodynamics are consistent with those established (from) petrogeology or from isotopic data. Calcite equilibrium favors precipitation of calcite early in the burial history. In-situ $\mathrm{pH}$ values of geopressured waters are 2-3 units lower than those measured at the wellhead. Low temperature and $\mathrm{pH}$ explain the absence of chlorite in the upper Texas coast. Chlorite and illite are the stable layer silicates in deep Frio sandstones.
\end{abstract}

15. Cheralyuh, E.B., "Geothermodynamic conditions of the formation of hydrocarbon systems", Geol. Geokhim. Goruuch. Iskop., 1983, 61, 29. (Russian)

Abstract: Any geologic formation which contains insufficient 0 to oxidize all its components and organic or inorganic $H$ and $C$ has a potential for the generation of hydrocarbons. Sedimentary rocks with organic components of various origin and deep ultrabasic rocks containing metal oxides meet this requirements; $\mathrm{H}_{2} \mathrm{O}$ and $\mathrm{CO}_{2}$ are the source of $\mathrm{H}$ and $\mathrm{C}$ for the ultrabasic rocks. To depth $40 \mathrm{~km}$, the geochemical conditions are not sufficient for the generation of hydrocarbons. At depth 50-100 $\mathrm{km}$, the conditions are sufficient for the generation of $\mathrm{CH}_{4}$ 
and at $120-250 \mathrm{~km}$ the generation of petroleum takes $\mathrm{place}$.

16. Osif, T.L.; Hayden, C.G.; Foh, S.E.; Randolph,; P.L., "Effluent gas composition changes during production of geopressured brines.", Report, GRI81/0154; Order No. PB-83-194894. Avail NTIS From: Gov. Rep. Announce. Index (U.S.), 1983, 83(15), 3562. (English)

Abstract: The objective of this work is to evaluate the possibility that measurements of the hydrocarbons dissolved in brine produced from a geopressured aquifer will indicate possible accumulations of free gas or oil in the reservoir away from the ellbore.

17. Ishiwatari, M., "Thermal reaction of $\beta$-carotene. Part 1.", J. Anal. Appl. Pyrolysis, 1980, 2(2), 153. (English)

Abstract: $\beta$-Carotene was heated under vacuum at temperatures ranging from 200 to $350^{\circ}$ for 24 hours as a model of a geothermal reaction of carotenoids in sediments and of a thermal reaction of a highly conjugated polyene. Compounds with molecular weights of $138,240,346$, and 444 and isomers of $\beta$ carotene were obtained in addition to toluene, xylene, ionene, and 2,6-dimethylnaphthalene, which were reported previously as pyrolysis products of $\beta$-carotene. Possible reaction mechanisms for the formation of the pyrolysis products are given.

18. Kolodii, V.V., "Geothermobaric conditions and oil and gas contents of hydrostatic basins.", Geol i Geokhimiya Goryuch. Iskopaemykh. (Kiev), 1979, (52), 3. (Russian)

Abstract: The thermobaric function $T / P=a / H^{b}(T$ is temperature, $P$ is pressure in atmospheres, $H$ is depth in $\mathrm{km}$, $a$ and $b$ are coefficients) is used to analyze conditions of petroleum and gas (Hydrocarbon and inorganic) coexistence in geologic strata. The petroleum-organic gas region lies within the limits $T=0.127 \mathrm{P} / \mathrm{H}^{1.45}$ and $T=1.48 \mathrm{P} / \mathrm{H}^{0.92}$. At low $T / P$ petroleum can be found at $H=5-12 \mathrm{~km}$ and gas condensate even at $H=20 \mathrm{~km}$. At high $T / P$, gas condensate can be emplaced at $H$ $=0.5 \mathrm{~km}$.

19. Welte, D.H., "Organic geochemical studies on the formation of petroleum hydrocarbons in rocks of the middle Upper Rhine Graben.", Fortschr. Geol. Rheinl. Westfalen, 1979, 27(Inkohlung Geotherm.), 51. (German) 
Abstract: Determination of the maturity of hydrocarbons extractable from samples from 25 boreholes in the Upper Rhine Graben indicate that 6 Tertiary formations had source rock properties. Certain Mesozoic strata penetrating near the rim of the Graben were also promising. In the Tertiary sediments, the onset of hydrocarbon formation depends on regional geothermal gradients, occurring at different depths and stratagraphic levels in different regions. The initiation of hydrocarbon formation occurs at greater depths and higher temperatures in cooler wells, owing to the smaller geothermal gradients. The face of the reservoir rock is also significant in the initiation of hydrocabon formation.

20. Gregory, A.R., "Engineering parameters used in geopressured geothermal fairway evaluation and test-well site location. Frio formation, Texas Gulf Coast." , Proc. $=$ Geopressured Geotherm. Energy Conf., 1977, 3rd(Vol.1), GI/349. (English)

Abstract: The history of gas-condensate production from geopressured reservoirs in the Chocolate Bayou field, near the Austin Bayou Prospect, shows that deliverable hydrocarbons is high in the early life of the reservoirs but drops sharply as pressure declines. The average geothermal gradient is $1.80 / 100$ $\mathrm{ft}$ and the reservoir pressure gradients are $0.465-0.98 \mathrm{psia} / \mathrm{ft}$ for depths below $10,000 \mathrm{ft}$. Salinity of the water is 40,000$80,000 \mathrm{ppm}$, and $\mathrm{CH}_{4}$ [74-82-8] content is 25-45 $\mathrm{ft}^{3} / \mathrm{bb}$ water. The effective gas permeabilities determined from the production flow test are estimated.

21. Volgyi, L., "The role of geothermal conditions and hydrocarbon prognostics in Hungary.", Acta Geol. Acad. Sci. Hung., 1977, 21(1-3), 143. (English)

Abstract: The formation, migration, preservation, and decomposition of hydrocarbons of Hungarian deposits are discussed in relation to geothermal conditions. The heating time of these formations was relatively short, and thus the major part of hydrocarbons didn't decompose even at high temperatures. The oil and gas deposits are assigned to different temperaturedepth horizons, i.e., a classification according to company. The peculiar geothermal position of Hungary is favorable for hydrocarbon formation and migration, especially for the Neogene sequence.

22. Deroo, G.; Powell, T.G., "The oil sands deposits of Alberta: their origin and geochemical history.", $0 i 1$ Sand $0 i 1$ Shale Chem., 1978, Proc. Symp., 
11. (English)

Abstract: The heavy oil deposits (oil sands) and the heavy conventional oil (conventionally producible Lloydminster heavy oils) of eastern Alberta resemble chemically the conventional oils in Lower Cretaceous (Mannville) reservoirs in the central part of the basin and as such differ in origin from the devonian oils. They are less mature than the contemporaneous oils to the west. Although their immaturity partially accounts for their heavy character, secondary processes such as biodegradation, water washing, secondary migration of light components, and possibly some inorganic oxidation result in the concentration of heavy ends with the ultimate formation of solid bitumen. In the main oil field area, certain oils located beneath the unconformity seperating the Mannville Group from the underlying rocks are altered as a result of secondary migration of the lightest components from their reservoirs to structurally higher reservoirs. The geochemically defined maturation state of the oils in zones with comparable geothermal gradients corresponds to their respective depths of burial. In the heavy oil zone, to the north and east of the main field area, all oils have undergone less maturation than those in the main field area. In addition to the effects of secondary migration, the aromatics from these oils have undergone degradation by water washing and inorganic oxidation which are associated with the biodegradation of the alkanes. These effects are at a maximum in the reservoirs closest to the Cretaceous unconformity even if the biodegradation of the $n$ alkanes had not reached the most advanced stage. The unconformity probably corresponds to an aquifer and controls the distribution and alteration of hydrocarbons in its vicinity.

23. Saxby, J.D., "The organic geochemistry of oil and gas generation and its application to Bass Strait and the Northwest Shelf.", APEA J>, 1978, 18(1), 137. (English)

Abstract: Thermal decomposition and subsequent alteration of buried organic matter are sufficient to explain the occurance of hydrocarbon deposits; the formation of oil and gas from kerogen requires that a temperature high enough for thermal decomposition must have resulted from the total depth of sediments and the geothermal gradient. Lipid-derived kerogen, high in $\mathrm{H}$, is likely to give oil; lignin-derived kerogen, low in $\mathrm{H}$, to give gas. Heavy oils are formed from light oils by bacterial attack in reservoirs at $<100^{\circ}$. Exploration should be 
conducted in basins where aliphatic organics are at present being subjected for the first time to temperatures $>140^{\circ}$, as through rapid burial in a bisin with a high geothermal gradient or through localized heating which is increasing the geothermal gradient. In the Gippsland Basin, generation of $0 i 1$ and gas in the lower Latrobe group is indicated; in the Rankin Platform of the Northwest Shelf, a deep source at $>4000 \mathrm{~m}$ is suggested for the gas and condensate.

24. Lorenson, L.E.; Walkup, C.M.; Mones, E.T., "Polymeric and composite materials for use in systems utilizing hot, flowing geothermal brine.", Proc. U.N. Symp. Dev. Use Geotherm. Resour., 1976, 2nd, v3, 1725. (English)

\begin{abstract}
Results of a materials selection program are reported for the utilization of hot geothermal brine to produce electric power. The presence of water-resistive groups such as imide, amide, or ester is detrimental even in very thermally stable polymers. In field tests with a flowing well, a fluorocarbon polymer exhibits promising resistance to erosion and scale deposition, which is very important in high solid content brines.
\end{abstract}

25. Paraschiv, D.; Cristian, M., "Effect of the geothermic factor on the formation of hydrocarbon deposits of Romania.", Stud. Cercet. Geol., Geofiz., Geogr., Ser. Geol., 1976, 21, 45. (Rumanian)

Abstract: The relations between formation, migration, and accumulation of hydrocarbons and geothermal gradient were observed. Regions having geothermal gradients of $3-6^{0} / 100 \mathrm{~m}$ contain large petroleum and natural gas deposits.

26. Freiberg, E.G., "Criteria for reconstructing pa;eogeological carbonization processes of organic substances.", Z. Angew. Geol., 1977, 23(7), 317. (German)

Abstract: Criteria for reconstructing paleogeological processes can be derived from the paleogeothermal history of development, the depression of sedimentary rocks and their geothermal load by magmatic influences, the analysis of relative phases of upheaval and periods of coalification, and analysis of hydrocarbon migration in different horizons.

27. Bishop, H.K., "Geothermal test by San Diego Gas \& Electric Co., Bur. Mines Open File Rep. (U.S.), OFR 128-76, Proc-Workshop Mater. Probl. Assoc. Dev. Geotherm. Energy Syst..2 2nd, 1976, PB-261 349, 63. (English) 
Abstract: Developments of methods to use the geothermal resources at 2 areas of the Imperial Valley are reported. In the lst field, the possibility of heat extraction from the brine in a shell and tube heat exchangers for a resonable time without fouling was evaluated as were the methods of steam seperation from the geothermal brine. In the 2nd field, heatexchanger tests were conducted to determine the characteristics of the brine, especially scale deposition during the heat-exchange process.

28. George, A.E.; Banerjee, R.C.; Smiley, G.T.; Sawatzky, H., "Simulated geothermal maturation of Athabasca bitumen.", Bull. Can. Pet. Geol., 1977, 25(5), 1085. (English)

Abstract: Reductive thermal treatments converted the title bitumen to materials similar to the more mature cretaceous oils. The saturated hydrocarbons and aromatic bicyclics were studied in detail. The generayion of isoprenoid hydrocarbons was observed. The optical activities of the oils investigated and the bitumen products showed interesting analogies. Athabasca bitumem is an immature material.

29. Segienko, S.I., "Effect of a heat field on the petroleum-gas contents of Mesozoic formations of the western Siberian platform", Izv. Akad. Nauk SSSR, Ser. Geol., 1977, (1), 104. (Russian)

Abstract: The thermal conditions and the important stages in the development of the heat fields in the western Seberian platform are discussed. Consolidation of the earth crust and mantle is the main source of heat necessary for the formation and transformation of hydrocarbons in the strata. The heat flow rate is an important factor in determining the nature of the hydrocarbon deposits. Heat flow rates of approx. 1.45 and

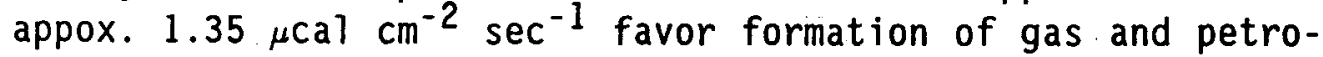
leum deposits, respctively, whereas lower heat flow rates generally indicate absence of all hydrocarbons. The type of original organic matter is the main factor in determining phisicochemical properties of the hydrocarbons. Subsequent catagenesis is of secondary importance. The fundamental properties of the hydrocarbons, as indicated by density, are determined by both temperature and heat flow rate. The density decreases with increasing zone temperatures. Maximum values are found only in regions where heat flow rate is $<1.29 \mu \mathrm{cal}$ $\mathrm{cm}^{-2} \mathrm{sec}^{-1}$. The heat field is the most important geophysical 
factor affecting formation, chemical composition, preservation and destruction of hydrocarbon deposits in the earth's crust.

30. Rhead, M.M.; Eglinton, G.; Draffan, G.H., "Hydrocarbons produced by the thermal alteration of cholesterol under conditions simulating the maturation of sediments.", Chem. Geol., 1971, 8(4), 277. (English)

Abstract: Thermal treatment of 4-14C-cholesterol incorporated in pulverized Green River Shale (Eocene) resulted in the formation of a number of $14 \mathrm{C}$ labeled hydrocarbons. Major products were labeled cholest-4-ene and labeled cholest-5-ene. These were probaly intermediates in the formation of labeled $5 . \alpha$ - and 5. $\beta$-cholestanes which were produced in significant amounts. Labeled biolipids were converted into hydrocarbons, some of which are widespread in ancient sediments and crude oils. Thermal treatment in the laboratory may simulate the process of maturation which seems to occur over millions of years in burial sediments. Labeled biolipid allowed the use of an organic-rich shale; the labeled products were readily detected and isolated.

31. Erofeev, V.F., "Geothermal activity of the earth and distribution of hydrocarbon deposits." Sov. Geol., 1970, 13(11), 142. (Russian)

Abstract: The relation is discussed between contours of geothermal fields and oil-gas zones in the Lower Carboniferous terrigenous formations of Volga-Ural Basinic Composition of the hydrocarbons $\left(\mathrm{CH}_{4}\right.$, paraffins) is related to the temperature of the area. A geoisotherm map of the Bashirsk horizon shows the relation between coefficients of gas-oil content and isohypsometrics.

32. Bayliss, G.S., "Formation of pristane, phytane, and related isoprenoid hydrocarbons by thermal degredation of chlorophy11. "Amer. Chem. Soc., Div. Petrol. Chem. Prep., 1968, 13(2), F117. (English)

Abstract: Isoprenoid hydrocarbons in crude oils and oil-shale may have formed from the phytol component of chlorophyll by sequences of hydrolysis, reduction, oxidation, and decarboxylation. 2,6,10,14-Tetramethylhexadecane (phytane), 2,6,10,14tetramethylpentadecane (pristane), and related isoprenoid hydrocarbons were prepared by thermal cleavage of isolated and purified chlorophylls. The hydrocarbon products generated in the high-temperature, high-pressure solvent hydrogenolys is of an algal chlorophyll differ from those formed from an alfalfa 
chlorophyl1. The algal chlorophyll gave phytane as the major product, whereas the alfalfa chlorophyll yielded more pristane and lower isoprenoid homologs. Olefinic isoprenoid hydrocarbons were also detected by mass spectrometry. Analysis of the algal chlorophyll products showed a predominance of the $\mathrm{C} 15$ monoolefinic isoprenoid hydrocarbon, while the alfalfa chlorophyll products indicated a $\mathrm{C} 17$ unsaturated compound. Both chlorophylls gave uv spectraconsistent with chlorophyll a. The mechanisms by which these hydrocarbons are produced are discussed, with emphasis on the significance of this work to geothermal diagenesis. The isoprenoid hydrocarbons present in oil-shale bitumen and those produced in the hydrogenolysis of oil-shale kerogen are compared.

\section{D.4. Models}

Any acceptable model of Gulf Coast geothermal/geopressure formations must explain the following observations:

1. Every sample of brine examined from DOE wells of opportunity, DOE design wells, and water producing commercial wells producing from below the geopressured horizon along the U.S. Gulf coast contained aromatic compounds. Where the amounts of cryocondensate collected could be subjected to gas chromatographic mass spectrographic analysis, i.e., the L.R. Sweezy, Gladys McCall, and Pleasant Bayou wells, the cryocondensate consisted of a complex mixture of more than ninety aromatic compounds ranging in complexity from benzene to polyalkyl substituted anthracenes.

2. For those $D O E$ design wells which were studied for an extended period of time, i.e., L.R. Sweezy, Gladys McCall, and Pleasant Bayou, the cryocondensate concentration increased with cumulative brine volume.

3. Two of the design wells studied, i.e., L.R. Sweezy and Gladys McCall, began to produce heavy oil after they had produced several million barrels of brine.

The ubiquitous presence of aromatic compounds in brines from below the geopressure horizon is probably related more to the temperatures of such formations than to their pressures. In addition to the accepted belief that aromatic compounds are a consequence of diagenesis, a second method of formation could involve the shale catalyzed cyclization of alkanes in reactions of the following types

$$
\underset{\substack{n-\mathrm{C}_{10} \mathrm{H}_{22} \\ \text {-decane }}}{\rightleftarrows} \underset{\text { benzene }}{\mathrm{C}_{6} \mathrm{H}_{6}(1)}+\underset{\text { methane }}{4 \mathrm{CH}_{4}}
$$


or

$$
\underset{\text { napthalein }}{\mathrm{n}-\mathrm{C}_{17} \mathrm{H}_{36}}(1) \quad \underset{\text { methane }}{\mathrm{C}_{10} \mathrm{H}_{8}}(1)
$$

or

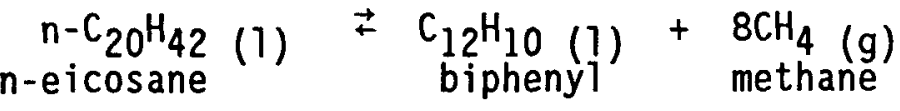

The values of $\Delta G_{420 K}^{0}$ for Equations $1-3$ are $-163.7,-324.1$, and -359.0 $\mathrm{kJ} / \mathrm{mol}$, respectively, under geothermal/geopressure conditions. While a negative value for $\Delta G_{420 K}$ is indicative of a negative value for $\Delta G_{420 K}$ and a thermodynamically spontaneous reaction, there is no way, in the absence of experimental data, to predict the rates of such reactions. However one can assume that on a geologic time scale at geothermal/geopressure temperatures such reactions would at lest be approaching equilibrium if equilibrium had not been attained.

The ubiquitous presence of aromatic compounds in geothermal/geopressure brines would seem to indicate that ether they were washed from oil (s) migrating through the brine containing formation or they were partitioned between oil residues in adjacent formation and the brines. The observed increase in cryocondensate concentration with brine production from geothermal/geopressured wells over relatively short periods of time would seem to support the later hypothesis, as does the production of oil from geothermal/geopressure wells after a period of brine flow.

We propose the following scenario (or model) to explain the observations listed above at all geothermal/geopressured wells studied. Figure D.1 illustrates what we believe to be the conditions prevalent in most if not all brine containing geothermal/geopressure formations prior to drilling.

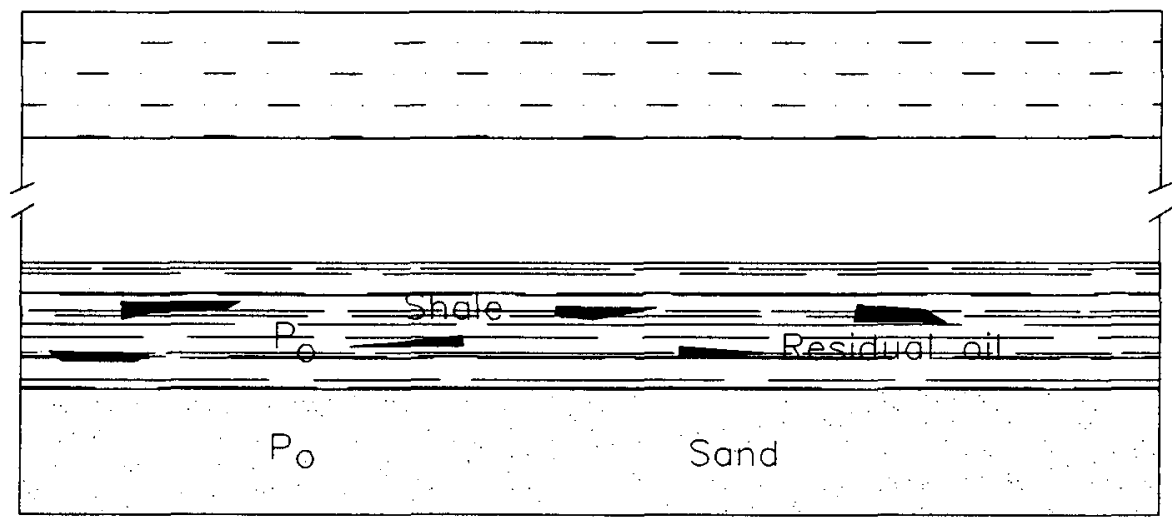

Figure D.1. Geothermal/geopressure formation prior to drilling. 
As indicated in Figure D.1., we believe that the shale adjacent to the brine containing sandstone contains greater or lesser amounts of residual oil. This oil is the source of the initial concentration of aromatic compounds observed in the brine. Over geologic time, the aromatics are partitioned between water in the shale, and ultimately the brine, and the oil. This is consistent with residual oil observed in shale cores from the L.R. Sweezy well and the relatively high aqueous solubility exhibited by aromatic compounds. As indicated in Figure $D .1$, the pressure, $P_{0}$, in the sandstone and shale formations are essentially the same.

Following drilling and with brine removal the scenario changes as depicted in Figure D.2. The removal of brine from the sandstone formation causes a drop in pressure from $P_{0}$ to $P_{b}$. A corresponding pressure drop occurs in the adjacent shale from $P_{0}$ to $P_{S}$, where $P_{0}>P_{s}>P_{b}$. Under the influence of the pressure gradient the residual oil either moves into the sand formation around the well piping, or directly across the shale/sandstone boundary.

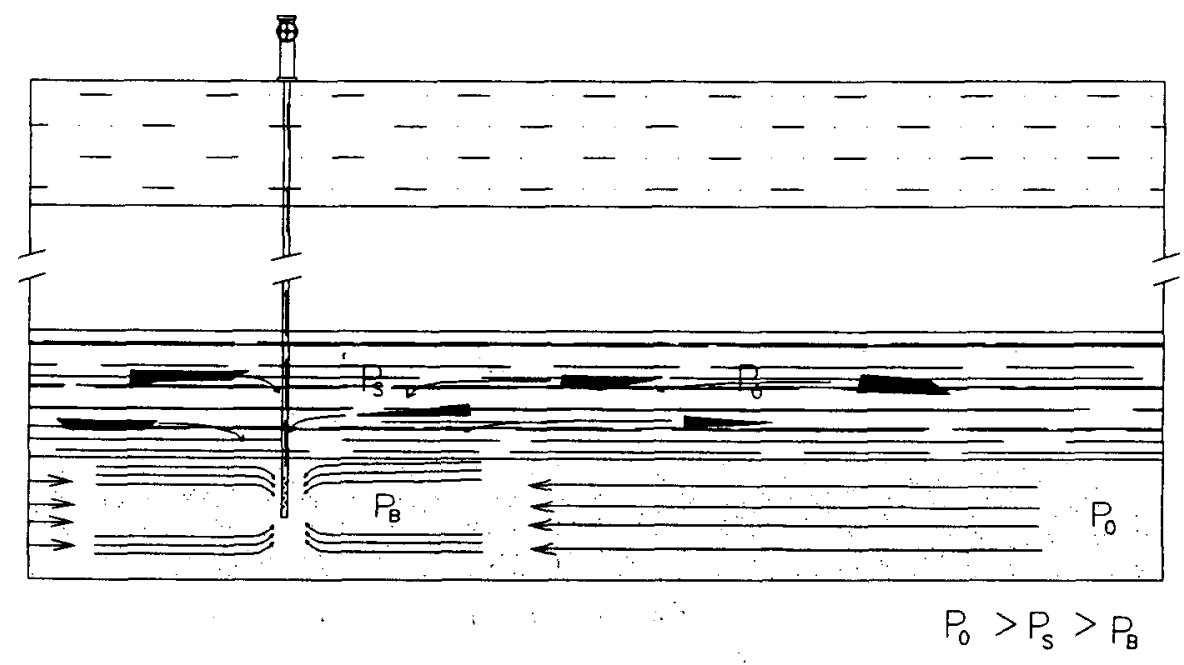

Figure D.2. Post drilling formation conditions.

The aromatic rich oil which has entered the sandstone formation provides a source of additional aromatics through extraction that shows up in the surface brine as an increase in cryocondensate. Since more and more oil enters the sandstone with brine production the amount of cryocondensate increases with the cumulative brine production as experimentally observed. 
Whether or not oil is produced from the well depends upon the amount of residual oil in the shale, the amount of oil that entered the sandstone formation from the shale, the location of the perforations in the production piping, and numerous other formation factors. Figure D.3 shows what we believe to be the case for the Pleasant Bayou well at the time of shut-in.

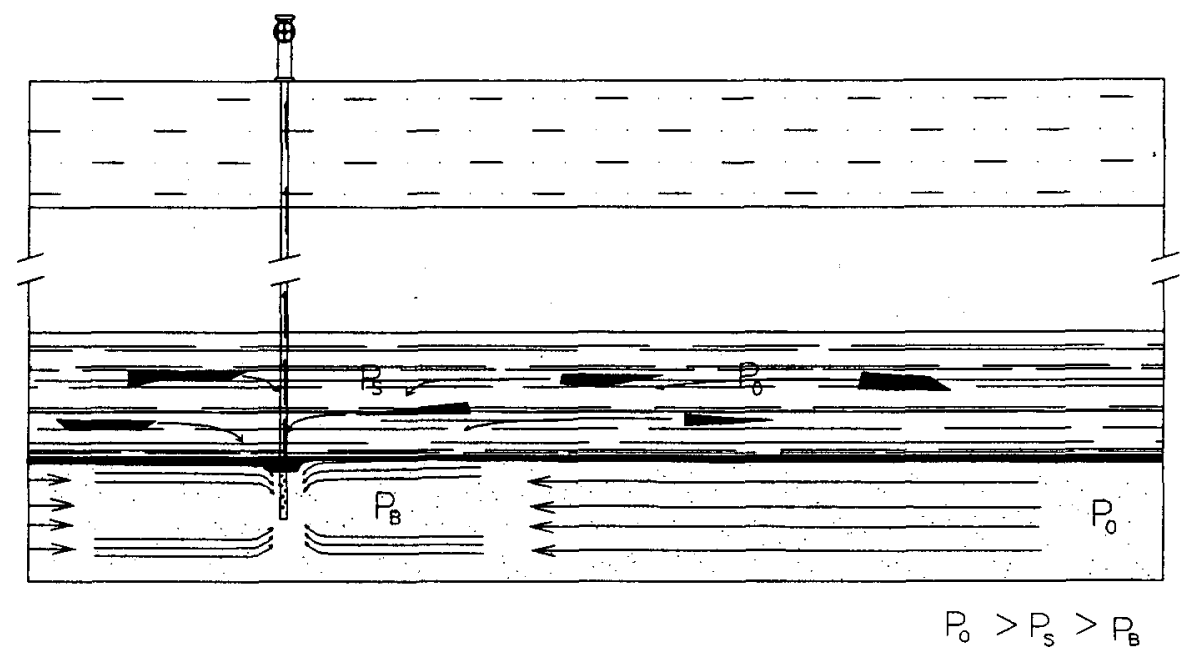

Figure D.3. The proposed conditions for the Pleasant Bayou well at the time of shut-in.

\section{D.5. Suggested experiments}

Two experiments that would lend support to the above scenario (model) for the formation and fate of the aromatic compounds are

1. Experiments should be conducted that involve the sealing of an aliphatic hydrocarbon, such as $n$-decane, in tubes with geothermal/geopressure shale, at elevated temperatures for significant period of time to ascertain whether reactions of the type

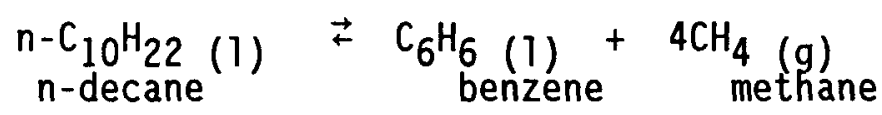

can be caused to occur in the laboratory.

2. The production tubing of the Pleasant Bayou well should be perforated as near the shale/sandstone interface as can be achieved to ascertain whether or not oil can be produced. 


\section{E. Monitor for Aliphatic Hydrocarbons}

During the period covered by the cooperative agreement no aliphatic compounds, other than those exsolved from the brines $\left(\mathrm{CH}_{4}, \mathrm{C}_{2} \mathrm{H}_{6}\right.$, etc.), were encountered at any flowing DOE geopressured well. 


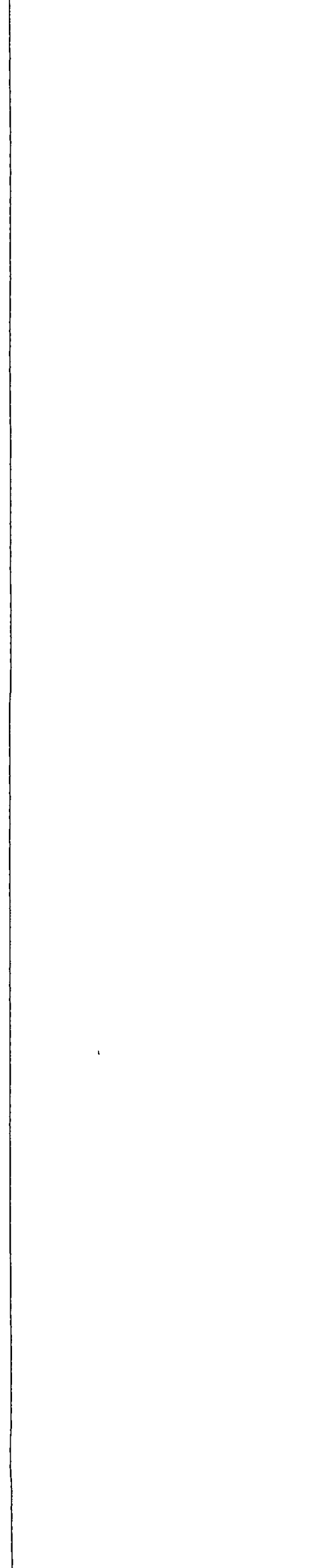

$$
4
$$
}

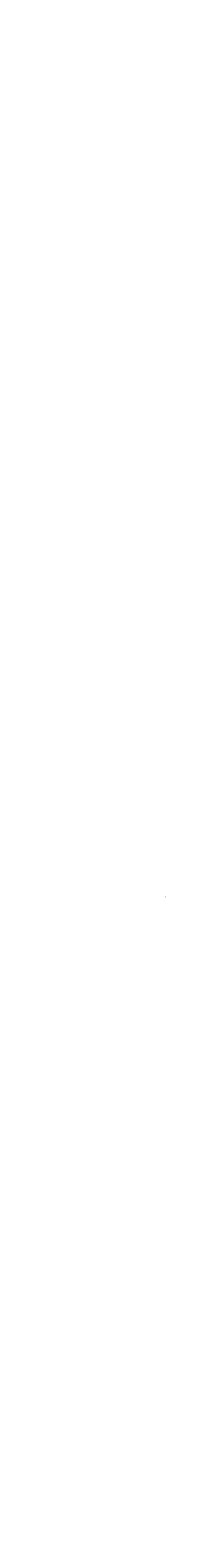




\section{F. Development of a pH Meter Probe}

\section{F.1. Introduction}

An important property of geothermal brines is $\mathrm{pH}$, specifically the increase in $\mathrm{pH}$ as they move from the geothermal/geopressure formation to the earth's surface. This increased $\mathrm{pH}$, which can amount to 2-3 pH units, is cause by the desorption of dissolved $\mathrm{CO}_{2}$ from the brine. The increased $\mathrm{pH}$ and the corresponding increase in the hydroxide ion concentration, $\left[\mathrm{OH}^{1-}\right]$, in the brine is an important factor in scale formation.

A pH probe, capable of measuring the change in $\mathrm{pH}$ with brine movement would be a valuable asset in the study of the chemistry of geothermal/geopressure brines.

\section{F.2. Theory}

$\mathrm{pH}$ is defined by

$$
\mathrm{pH}=-\log \left(\mathrm{a}_{\mathrm{H}} \mathrm{l}+\right)
$$

where $a_{H}{ }^{1+}$ is the activity of the hydrogen (hydronium) ion. The activity of the hydrogen ion can be expressed

$$
a_{H} 1+=f_{H} 1+\cdot\left[H^{1+}\right]
$$

where $\mathrm{f}_{\mathrm{H}^{1+}}$ and $\left[\mathrm{H}^{\mathrm{l}}\right]$ are the activity coefficient and molar concentration for the hydrogen ion, respectively. The activity coefficient for an ion in solution depends primarily upon the ionic strength, $\mu$ of the solution. At the ionic strengths of most geothermal/geopressure brines activity coefficients cannot be calculated and must be determined experimentally.

The $\mathrm{pH}$ of a solution that contains dissolved $\mathrm{CO}_{2}$ is primarily determined by the equilibrium

$$
\mathrm{CO}_{2}+\mathrm{H}_{2} \mathrm{O} \rightleftarrows \mathrm{HCO}_{3}^{1-}+\mathrm{H}^{1+}
$$

for which $K_{1}=2.64 \times 10^{-7}$ at $25^{\circ} \mathrm{C}$ and increases slightly with an increase in temperature. Figure $F . l$ is a plot of $k_{1}$ for Equation 1 as a function of temperature. 


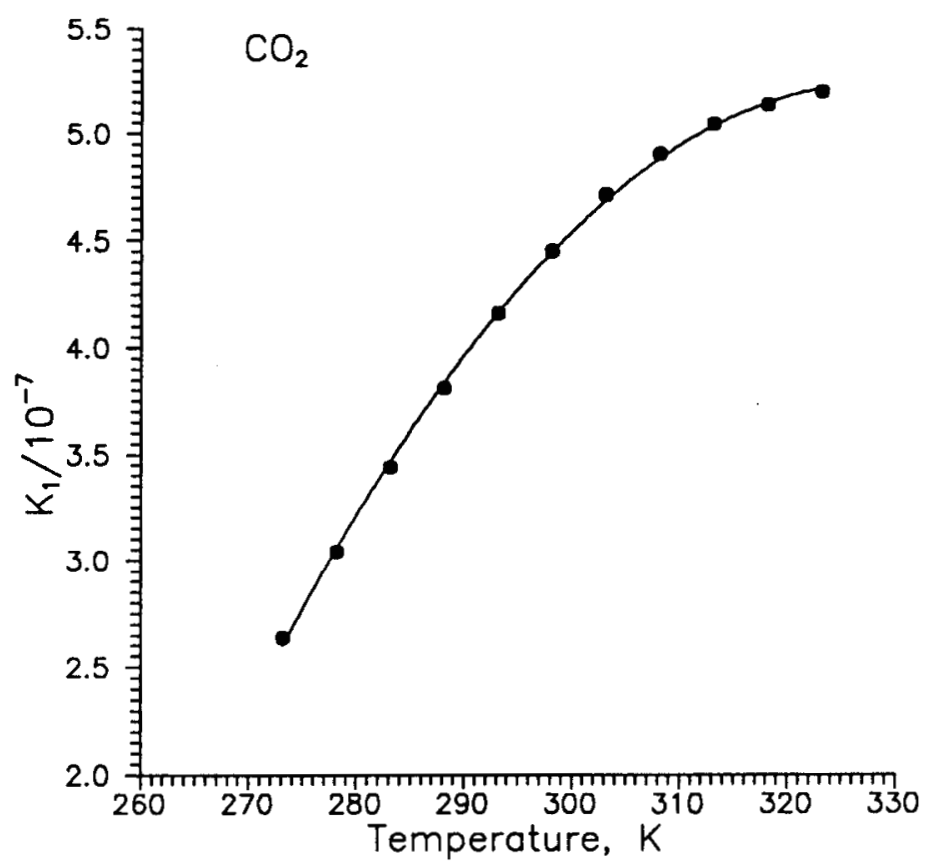

Figure F.1. $\mathrm{K}_{1}$ for $\mathrm{CO}_{2}$ in water as a function of temperature.

For Equation 1 the mass action expression, excluding activity and fugacity coefficients, is given by

$$
K_{1}=\frac{\left[\mathrm{HCO}_{3}^{--}\right]\left[\mathrm{H}^{1+}\right]}{\mathrm{PCO}_{2}}
$$

where $\left[\mathrm{HCO}_{3}^{-}\right]$and $\left[\mathrm{H}^{1+}\right]$ are the molar concentrations of $\mathrm{HCO}_{3}^{-}$and $\mathrm{H}^{1+}$, respectively, and $\mathrm{PCO}_{2}$ is the partial pressure of carbon dioxide.

When geopressured brine, which contains dissolved gases, undergoes a reduction in applied pressure, the dissolved gases, including $\mathrm{CO}_{2}$, are exsolved from the brine. It is this loss of $\mathrm{CO}_{2}$ that results in an increase in $\mathrm{pH}$ of the brine. The magnitude of the $\mathrm{pH}$ increase depends primarily on the concentration of $\mathrm{HCO}_{3}{ }^{-}$in the formation brine and the decrease in pressure on the brine.

The chemical reaction that occurs with a decrease in pressure is simply the reverse of Equation 1, i.e.,

or

$$
\mathrm{HCO}_{3}^{-}+\mathrm{H}^{\mathrm{I}} \rightarrow \mathrm{CO}_{2}+\mathrm{H}_{2} \mathrm{O}
$$

$$
\mathrm{HCO}_{3}^{1-} \rightarrow \mathrm{CO}_{2}+\mathrm{OH}^{1-}
$$


$\mathrm{pH}$ is generally measured electronically by means of an electrochemical cell of the general type

$$
\text { indicating electrode/reference electrode }
$$

In commercial $\mathrm{pH}$ meters the indicating electrode is usually a glass electrode while the reference electrode is usually a $\mathrm{Ag}-\mathrm{AgCl}$ electrode or a saturated calomel electrode, i.e.,

$$
\text { glass electrode } \mathrm{H}_{3} \mathrm{O}^{1+}\left(\mathrm{m}_{1}\right), \mathrm{X}^{1-}\left(\mathrm{m}_{1}\right) \mid \mathrm{KCl} \text { (satd.) }\left|\mathrm{Hg}_{2} \mathrm{Cl}_{2}, \mathrm{Hg}(1)\right| \mathrm{Pt}
$$

A glass electrode is delicate and impractical for use as an indicating electrode in applications that involve harsh conditions such as high ionic strength, and high temperatures and/or pressures. For applications that involve harsh conditions, the availability of chemically sensitive semiconductor devices (CSSD) offers an attractive alternative for constructing a harsh environment $\mathrm{pH}$ probe.

One device currently used in solid state $\mathrm{pH}$ meters is an ion sensitive field effect transistor (ISFET). When used in conjunction with a suitable reference electrode the ISFET functions as the indicating electrode in a cell of the type

$$
\text { ISFET|reference electrode }
$$

This research involves an attempt to construct a harsh environment $\mathrm{pH}$ probe based upon an electrochemical cell of the type shown in Equation 8.

\section{F.3. Experimental}

Experimental approach: The approach which was used to attempt to develop a harsh environment $\mathrm{pH}$ probe was to first try to find and indicating electrode which would function under the harsh conditions found in geothermal/geopressure wells. Secondly would be the selection of a suitable reference electrode. This approach was used since if a suitable indicating electrode could not be found all other considerations would be academic.

pH probe and high-pressure cell: A pH probe and high-pressure cell, shown in Figures F.2 and F.3, were constructed by Quality Machine and Supply of Lafayette, LA and by USL personnel. The indicating electrode consisted of a hydrogen ion, $H^{1+}$, sensitive field effect transistor furnished to USL by $D r$. Randolph Turpin, CEO of the Chemfet Corporation of Bellevue, WA. For convenience, the reference electrode was a $\mathrm{Ag}-\mathrm{AgCl}$ electrode. 


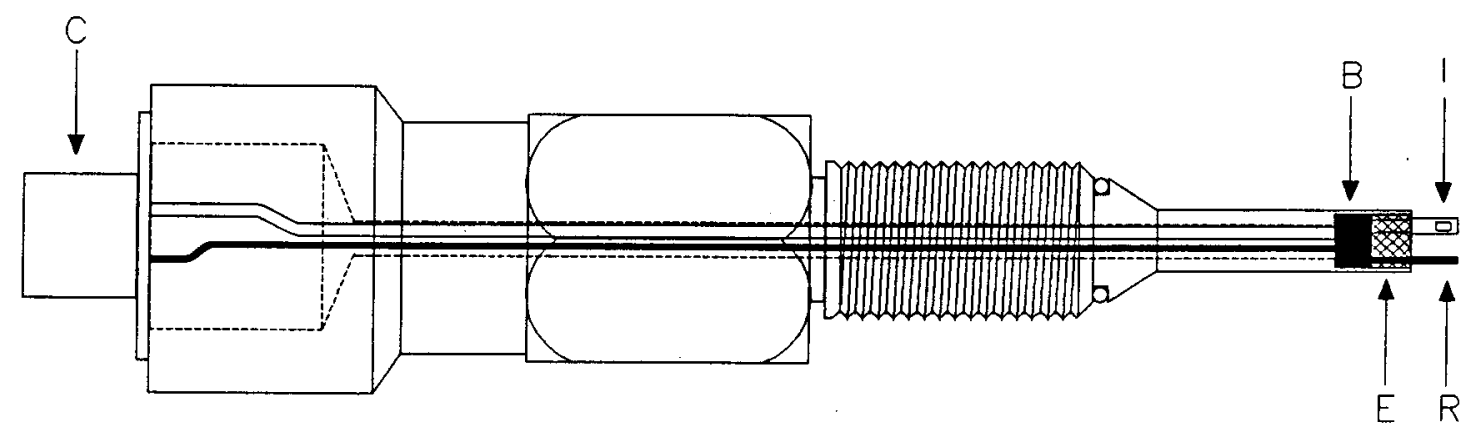

Figure F.2 Harsh environment pH probe. $I=I S F E T, R=$ reference electrode $(\mathrm{Ag} / \mathrm{AgCl}), \mathrm{B}=$ three hole bushing, $\mathrm{E}=$ degassed slow setting epoxy adhesive, $\mathrm{C}$ = three pin electrical connector.

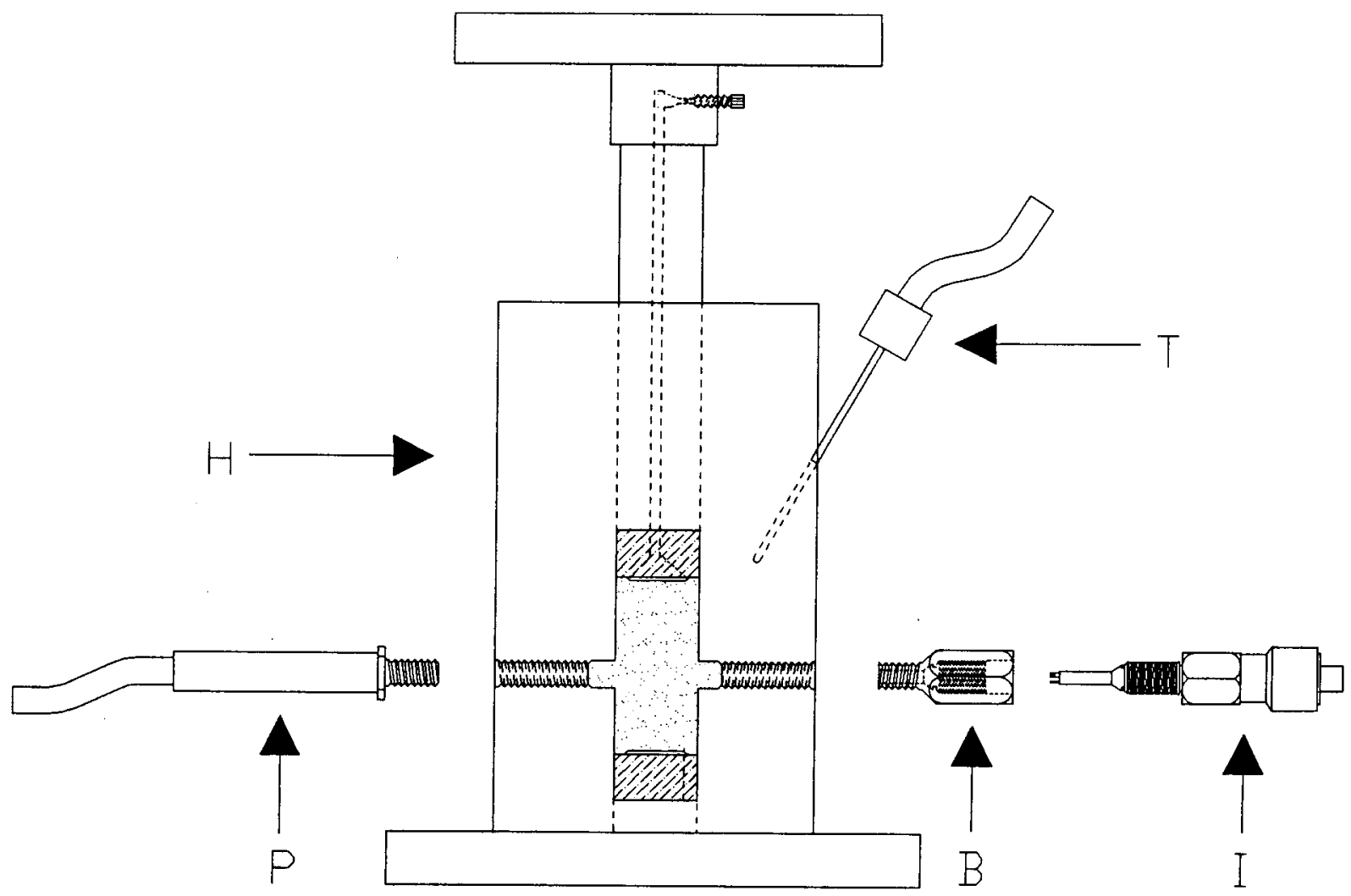

Figure F.3. High-pressure set-up. $H=$ high-pressure cell, $T=$ thermocouple, $P$ $=$ pressure transducer, $B=$ special coupler, $I=$ ISFET $\mathrm{pH}$ probe. 
Results: Figure F.4 is a plot of the electrical response of the pH probe as a function of $\mathrm{pH}$.

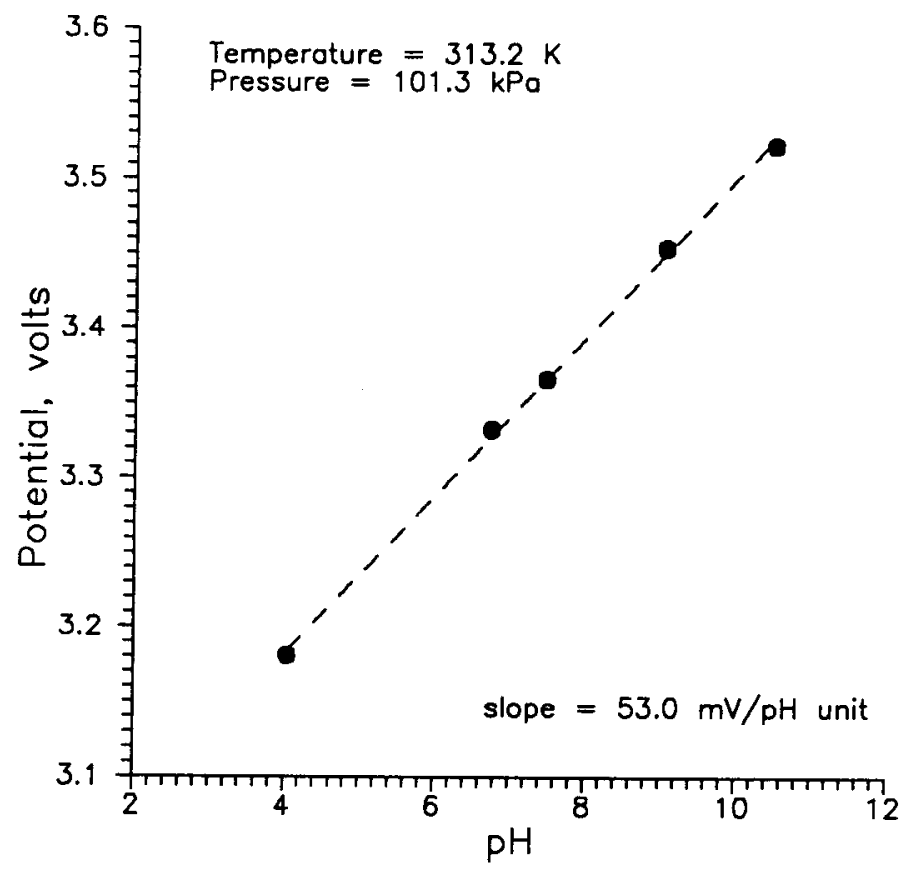

Figure F.4. Electrical response of the $\mathrm{pH}$ probe as a function of $\mathrm{pH} .[\mathrm{NaCl}]=$ $0.100 \mathrm{M}\left(\mathrm{mol} \mathrm{dm} \mathrm{dm}^{-3}\right), T=298.2 \mathrm{~K}\left(25.0^{\circ} \mathrm{C}\right), \mathrm{P}=101.3 \mathrm{kPa}(1 \mathrm{~atm})$.

Figure F.5 indicates the stability of the pH probe as a function of immersion time.

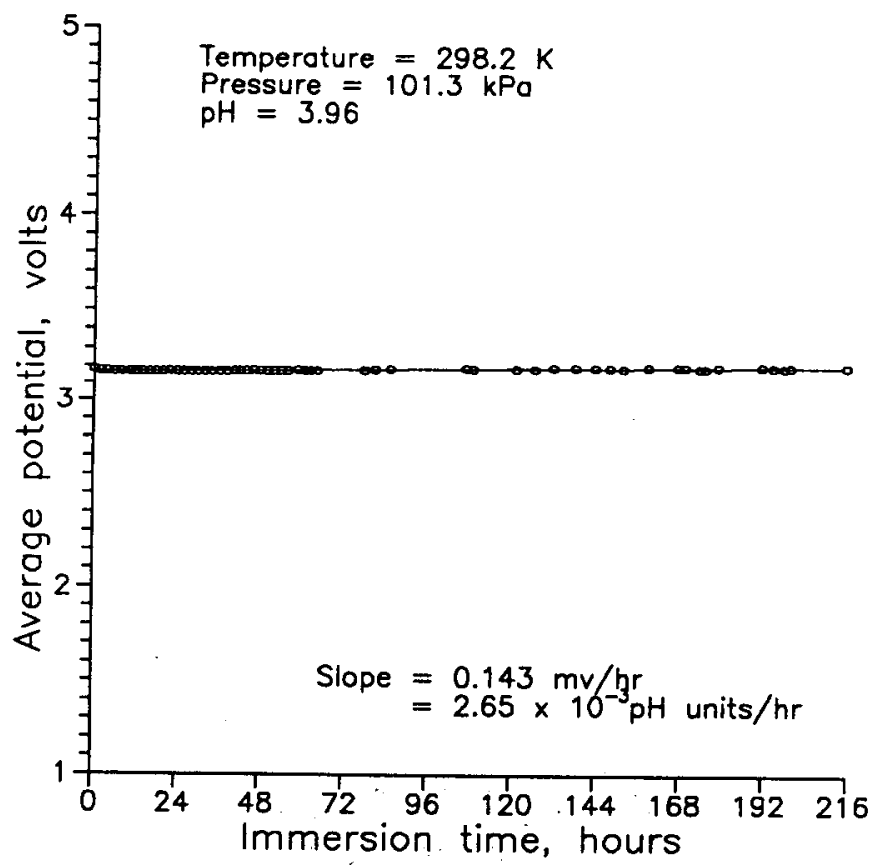

Figure F.5. Average potential of $\mathrm{pH}$ probe as a function of immersion time. $[\mathrm{NaCl}]=0.100 \mathrm{M}$. 
Figure $F .6$ is a plot of the potential of the probe as a function of temperature.

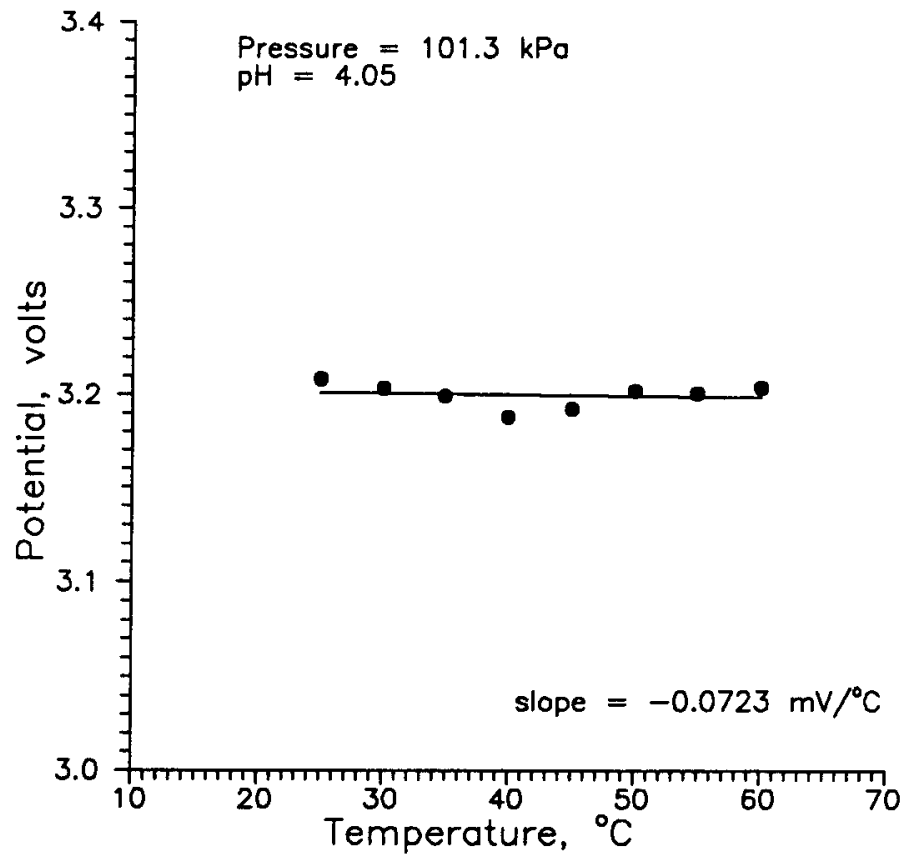

Figure F.6. Potential of $\mathrm{pH}$ probe as a function of temperature. $[\mathrm{NaCl}]=0.100$ M.

Figure F.7 is a plot of the potential of the $\mathrm{pH}$ probe as a function of pressure at two different temperatures.

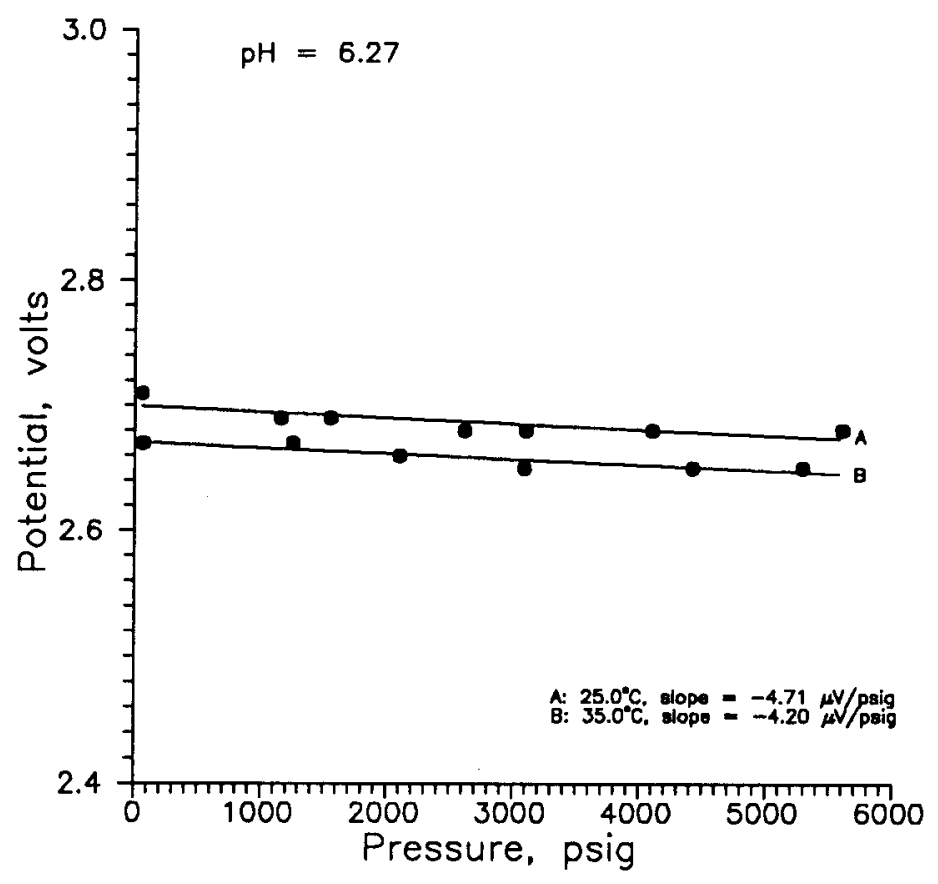

Figure F.7. Potential of the $\mathrm{pH}$ probe as a function of pressure. $[\mathrm{NaCl}]=$ $0.100 \mathrm{M}$. 
Discussion: We believe that the data shown in Figures F.4 through F.5 clearly indicate that a $\mathrm{pH}$ probe that uses an ISFET as the indicating electrode can be successfully designed and constructed. Furthermore we believe that such a probe will operate for a sustained period of time under harsh conditions; high ionic strength, temperature, and pressure.

Unfortunately, the only source of the ISFETs we could locate, The CHEMFET Corporation, entered into bankruptcy before we could bring this task to a successful conclusion. 


\section{G. Perform DOE Design Well Scrubber Analysis}

For completeness the time interval in this section extends from $4 / 22 / 89$ through $9 / 11 / 92$.

\section{G.1. Introduction}

At the request of DOE personnel, an inexpensive a gas scrubbing technique was developed to obtain the daily concentrations of cryocondensate in the brine from the Pleasant Bayou well.

\section{G.2. Theory}

According to Henry's law, when a gas is bubbled through a liquid solvent that has an affinity for one or more components in the gas, each component in the gas that is soluble in the solvent will establish an equilibrium given by Henry's law

$$
p_{i}=k_{j} x_{i}
$$

where $p_{i}$ is the partial pressure of component $i$ in the gas, $k_{i}$ is the Henry's law constant for the solvent and component $i$ at a specific temperature, and $x_{i}$ is the equilibrium concentration of component $i$ in the liquid solution phase.

The technique developed by USL, makes use of Equation 1. It is based upon the assumption that if a geopressured well flows at a constant rate and is in thermal equilibrium with its surroundings, that the ratio of cryocondensate components exsolved from the brine with the gas to the amount of cryocondensate components that remain in the brine should be constant. This assumption allows the daily concentration of the cryocondensate, $x_{d}$, to be calculated from the relationship

$$
x_{d}=x_{k}\left(A_{d} / A_{k}\right)
$$

where $x_{k}$ is the known concentration of cryocondensate obtained from a complete analysis from samples collected on a regular well site visit, and $A_{d}$ and $A_{k}$ are the gas chromatogram areas for a peak corresponding to a selected cryocondensate component, usually benzene.

\section{G.3. Equipment}

The gas scrubbing apparatus, shown in Figure G.1, designed and constructed at USL, was installed in a climate controlled facility at the Pleas- 
ant Bayou well site. Separator gas was expanded in the regulator ( $R$ ). The second stage pressure was kept at $20 \mathrm{psig}(137 \mathrm{kPa})$. In order to adjust the temperature of the gas, the separator gas was then flowed through a copper coil (C) which was in a water bath whose temperature was regulated by the surrounding environment. After the separator gas was expanded and thermostated, it was bubbled through PAO contained in a bottle in the scrubber (S). The scrubber consisted of a fixed upper portion and a removable lower portion. The two components were threaded together and sealed using two 0 -rings. Maximum surface contact between the gas and the solvent were achieved using a fritted metal bubbler immersed in the liquid. The fritted metal portion of the bubbler was attached to a length of stainless steal tubing which extends down from the top of the fixed portion of the scrubber. A bottle containing PAO was placed into the lower portion of the scrubber and brought into position when the scrubber was assembled. Gas exited through the side of the scrubber to the flow meter $(F)$. Using the flowmeter, the flow rate of sample gas was monitored and controlled by well site personnel.

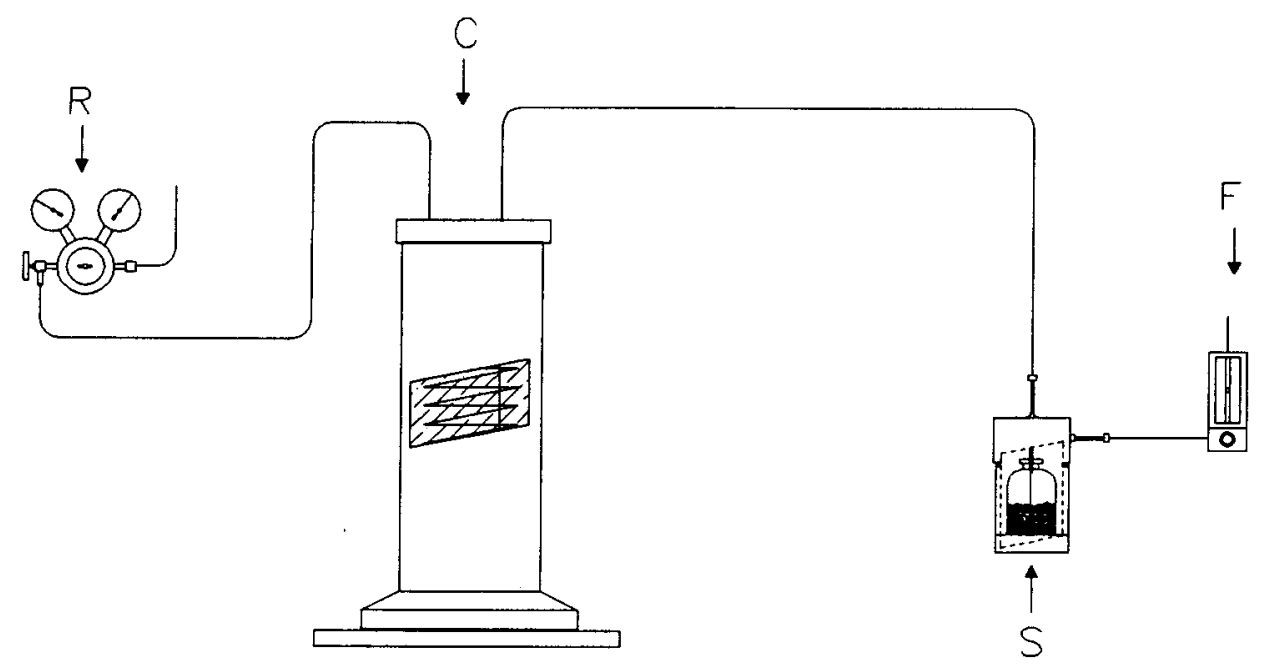

Figure G.1. Gas scrubbing equipment. $R=$ two stage gas regulator, $C=$ copper coil, $S=$ scrubber, $F=$ flow meter.

The bottles used were Wheaton $125 \mathrm{~cm}^{3}$ borosilicate glass serum bottles with a measured internal volume of $160.1 \pm 0.9 \mathrm{~cm}^{3}$. The bottles were sealed with an aluminum lined septum and aluminum center disk tear out caps.

\section{G.4. Sample collection procedure}

Prior to use, $40.65 \mathrm{~g}\left(50.00 \mathrm{~cm}^{3}\right)$ of PAO was weighed into each bottle. The bottles were then temporarily sealed with rubber stoppers for transport to the well site. A box of forty-two (42) prepared sample bottles were trans- 
ported to the Pleasant Bayou location on each sampling trip.

Pleasant Bayou well-site personnel changed the sample bottles each day the well was in operation. For consistency, sample changes were made at the same time each day. The removed bottles were quickly sealed with aluminum lined septa and aluminum caps. The septa and caps, were attached to the bottles using a crimping tool that was mounted near the scrubber. Each bottle was labeled with the date of the corresponding sample change. A new bottle was then placed into the lower portion of the scrubber, and the scrubber was reassembled. The system was checked for leaks following sample replacement. Leak detection was accomplished by comparing the gas flow rates through the system before and after sample replacement. Notations were made in the log book of the date, room temperature and time of each sample replacement. Samples were brought to USL for headspace gas chromatographic analysis.

\section{G.5. Sample analysis}

A series of twelve (12) calibration standards were prepared prior to analysis of each set of samples. The standards were prepared in the same type of bottles used in sampling. Microliter volumes $\left(\mathrm{mm}^{3}\right)$ of the solutes were added to the standards using a series of Hamilton microliter syringes. Immediately following addition of the solute, the standards were sealed using the same procedure used in sealing the samples. Six of the standards contained only diluent gas and solute vapor. Table G.1 lists the volumes of benzene and toluene contained in these standard.

Table G.1. Volumes of benzene and toluene used in vapor only standards.

\begin{tabular}{cc}
\hline Solute & Volume, $\mathrm{mm}^{3}$ \\
\hline Benzene & 0.5 \\
& 1.0 \\
Toluene & 1.5 \\
& 0.5 \\
& 1.0 \\
& 1.5
\end{tabular}

In addition to $50 \mathrm{~cm}^{3}$ of PAO, the other six bottles contained a $0.7 \mathrm{~cm}^{3}$ Pyrex covered stirring bar prior to the addition of the solutes. The volumes of solutes added to prepare these standards are listed in Table G.2. 
Table G.2. Volume of benzene and toluene used in standards containing PAO.

\begin{tabular}{cc}
\hline Solute & Volume, $\mathrm{mm}^{3}$ \\
\hline Benzene & 50 \\
& 100 \\
& 150 \\
Toluene & 50 \\
& 100 \\
& 150
\end{tabular}

Standards and samples were thermostated in a constant temperature shaking bath at $25.0^{\circ} \mathrm{C}$ for at least twenty-four (24) hours prior to analysis. Each sample was pressurized with diluent nitrogen gas to $16.00 \pm 0.10 \mathrm{psig}(110 \pm 0.7 \mathrm{kPa})$ preceding analysis. The diluent gas provided a positive pressure so that gas would flow from the headspace of the bottles. Analysis of a $254 \mathrm{~mm}^{3}$ volume of headspace gas from each bottle was carried out using gas chromatography. Chromatographic responses were plotted against system solute concentrations for each of the four types of standards. Daily solute concentrations were determined by normalizing the responses of the samples to the cryocondensate data.

\section{G.6. Results}

The daily scrubber data obtained from the Pleasant Bayou well from $4 / 22 / 89$ through $911 / 92$ is shown in Figure G.2.

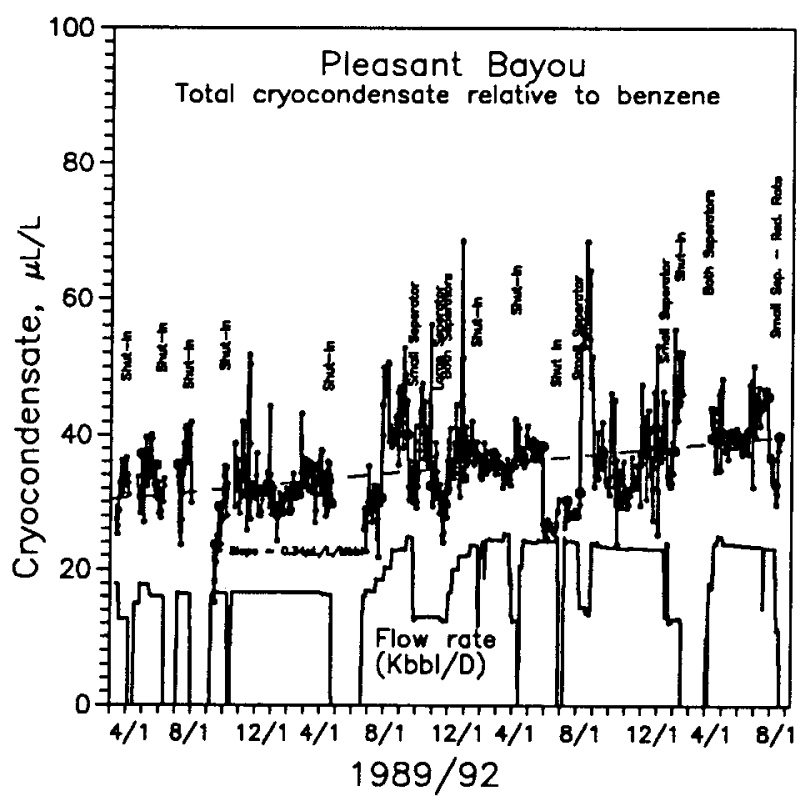

Figure G.2. Pleasant Bayou well cryocondensate concentration, in $\mu L /(L$ of brine) as a function of sample date. From 4/22/89 through 9/11/92. 
H. Removal and Disposition of Gas Scrubber Equipment at Pleasant Bayou Well

USL personnel removed the gas scrubbing equipment from the Pleasant Bayou well site on 10/10/92 as required. 


\section{Disposition of Archived Brines}

USL personnel transported ninety-nine gallons (99 gal) of archived geopressured brine to the Pleasant Bayou well site on December 18, 1992 where it was combined with brine from the Pleasant Bayou Well which will be disposed of by pumping it into the Pleasant Bayou well-site's brine disposal well, a manner consistent with state and Federal regulations. 


$$
60
$$$$
\text { (1) }
$$

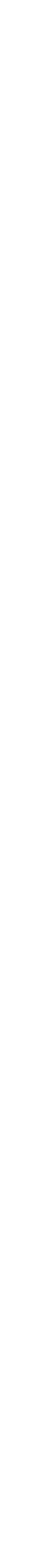




\section{Appendix A}

Computer Programs

\section{A-1. CRYOHYD.BAS}

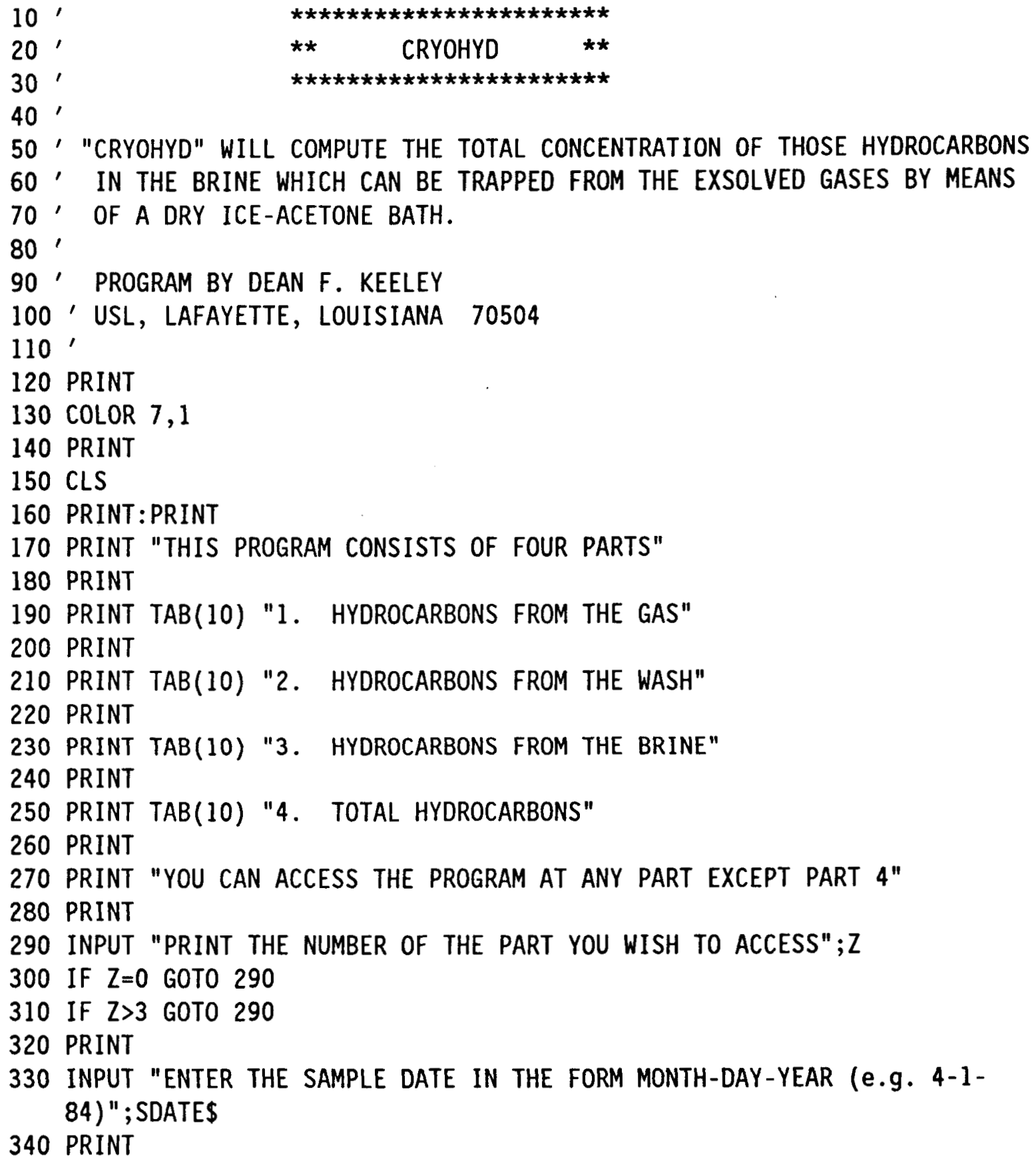


350 PRINT "ENTER THE NUMBER DESIGNATION FOR THE WELL SAMPLED"

360 PRINT

370 INPUT "GLADYS MCCALL $=1 \star \star \star \quad$ PLEASANT BAYOU $=2 "$; I

380 PRINT

390 IF I $=0$ GOTO 350

400 IF I>2 GOTO 350

410 IF $Z=1$ GOTO 480 ELSE 420

420 IF $Z=2$ GOTO 510 ELSE 430

430 IF $Z=3$ GOTO 1560

440 '

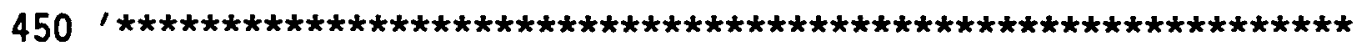

$4601 * *$ DATA INPUT FOR HYDROCARBONS RECOVERED FROM GAS $* *$

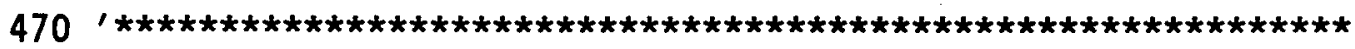

480 CLS

490 PRINT

500 INPUT "ENTER THE VOLUME OF THE CRYOGENIC CONDENSATE RECOVERED IN mL";VCC

510 PRINT

520 INPUT "ENTER THE VOLUME OF DRY GAS SAMPLED IN CU. FT. ";VGAS

530 PRINT

540 INPUT "ENTER THE BAROMETRIC PRESSURE IN TORRS";BP

550 PRINT

560 INPUT "ENTER THE INITIAL COLLECTION TEMPERATURE IN DEGREES C";TI

570 PRINT

580 INPUT "ENTER THE FINAL COLLECTION TEMPERATURE IN DEGREES C";TF

590 PRINT

600 INPUT "ENTER THE TEMPERATURE OF THE BRINE IN DEGREES F";TB

610 PRINT

620 INPUT "ENTER THE GAS/BRINE RATIO IN SCF/BBL";GBR

630 PRINT

640 INPUT "ENTER THE SEPERATOR PRESSURE IN PSI";PS

650 PRINT

660 IF I=1 GOTO 710 ELSE 670

670 IF I=2 GOTO 760

680 PRINT

$690^{\prime} \star * *$ SALINITY OF GLADYS MCCALL WELL***

700 PRINT

$710 S=88.9$

720 GOTO 790

730 PRINT

$740^{\prime} \star * \star$ SALINITY OF PLEASANT BAYOU WELL***

750 PRINT

$760 S=119.6$

770 GOTO 790

$780^{\prime} \star \star \star *$ CONVERSION OF BRINE TEMPERATURE TO DEGREES $c * \star \star$

$790 \mathrm{TC}=(\mathrm{TB}-32) / 1.8$ 
$800^{\prime} * \star *$ COMPUTATION OF THE VAPOR PRESSURE OF WATER ABOVE THE BRINE IN PSI*** 810 PZERO $=\operatorname{EXP}(2.303 *(7.9385-1650.32 /(T C+226.3)))$

820 DELTAP $=$ PZERO*S* .000538

830 PH20=PZERO-DELTAP

$840 \mathrm{PH} 20=\mathrm{PH} 20 * .01934$

850 PRINT

$860^{\prime} \star \star *$ CALCULATION OF THE MOLE FRACTION OF GAS ABOVE THE BRINE***

870 IF PS=0 GOTO 640

$880 X \mathrm{XAS}=(\mathrm{PS}-\mathrm{PH} 20) / \mathrm{PS}$

$890^{\prime} * \star \star *$ CALCULATION OF THE GAS/BRINE RATIO BASED ON DRY GAS AT 6OF \& 1 ATM*** $900 \mathrm{DGBR}=\mathrm{GBR} * X \mathrm{GAS}$

$910^{\prime} * * *$ CONVERSION OF THE SAMPLED GAS VOLUME TO $60 \mathrm{~F} \& 1$ ATM***

920 TAVE $=(T I+T F) / 2+273.15$

930 VGAS $=$ VGAS* $(B P / 760) *(288.71 /$ TAVE $)$

$940^{\prime * \star *}$ CALCULATION OF THE YIELD OF TRAPPED HYDROCARBONS IN UL/L OF BRINE*** 950 IF VGAS=0 GOTO 520

$960 \mathrm{HYDY}=(\mathrm{VCC} / \mathrm{VGAS}) * \mathrm{DGBR}$

$970 \mathrm{ULPL}=\mathrm{HYDY} * 6.29$

980 PRINT

990 A\$="THE UL OF HYDROCARBONS / L OF BRINE RECOVERED FROM THE GAS IS " $1000 B \$=" \mathrm{UL} / \mathrm{L} "$

1010 PRINT USING "\&";A\$;

1020 PRINT USING "\#\#.\#\#";ULPL;

1030 PRINT USING "\&";B\$

1040 PRINT

1050 PRINT

1060 PRINT "DO YOU WISH TO CONTINUE? ( $\mathrm{Y} / \mathrm{N})$ "

$1070 Z \$=I N P U T \$(1)$

1080 IF $Z \$=" Y "$ THEN 1130 ELSE 1090

1090 IF $2 \$=" y "$ THEN 1130 ELSE 2010

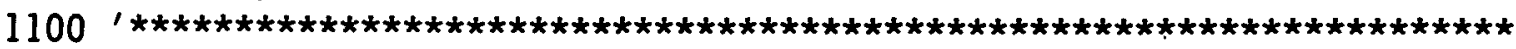

$1110^{\prime} * *$ DATA INPUT FOR HYDROCARBONS CONTAINED IN THE TRAP WASH **

1120 '

1130 PRINT

1140 INPUT "ENTER THE SLOPE OF THE BENZENE WASH CALIBRATION CURVE";BWSLP

1150 PRINT

1160 INPUT "ENTER THE INTERCEPT OF THE BENZENE WASH CALIBRATION CURVE";BWINT

1170 PRINT

1180 INPUT "ENTER THE A\% BENZENE FROM THE WASH GC";BW

1190 PRINT

1200 PRINT

$1210^{\prime} * * *$ CALCULATION OF BENZENE IN THE WASH IN UL/L OF BRINE***

1220 IF BWSLP=0 GOTO 1140

$1230 \mathrm{BWML}=(B W-B W I N T) /(B W S L P * 1000)$

1240 BWULPL $=(B W M L / V G A S) \star D G B R * 6.29$ 
1250 C $\$="$ THE UL OF BENZENE / L OF BRINE RECOVERED FROM THE WASH IS "

1260 PRINT USING "\&";C\$;

1270 PRINT USING "\#\#.\#\#";BWULPL;

1280 PRINT USING "\&";B\$

1290 PRINT

1300 PRINT

1310 INPUT "ENTER THE SLOPE OF THE TOLUENE WASH CALIBRATION CURVE";TWSLP

1320 PRINT

1330 INPUT "ENTER THE INTERCEPT OF THE TOLUENE WASH CALIBRATION CURVE";TWINT

1340 PRINT

1350 INPUT "ENTER THE A\% TOLUENE FROM THE WASH GC";TW

1360 PRINT

1370 PRINT

$1380^{\prime} * * *$ CALCULATION OF TOLUENE IN THE WASH IN UL/L OF BRINE***

1390 IF TWSLP=0 GOTO 1310

1400 TWML $=($ TW - TWINT $) /($ TWSLP $* 1000)$

1410 TWULPL $=(T W M L / V G A S) * D G B R * 6.29$

1420 D $\$="$ THE UL OF TOLUENE / L OF BRINE RECOVERED FROM THE WASH IS "

1430 PRINT USING "\&";D\$;

1440 PRINT USING "\#\#.\#\#";TWULPL;

1450 PRINT USING "\&";B\$

1460 PRINT

1470 PRINT

1480 PRINT "DO YOU WISH TO CONTINUE? ( $\mathrm{Y} / \mathrm{N})$ "

$1490 Y \$=I N P U T \$(1)$

1500 IF $Y \$=" Y "$ THEN 1520 ELSE 1510

1510 IF $Y \$=" y "$ THEN 1520 ELSE 2010

1520 PRINT

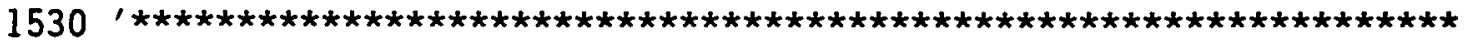

1540 '** DATA INPUT FOR HYDROCARBONS CONTAINED IN THE BRINES $\star *$

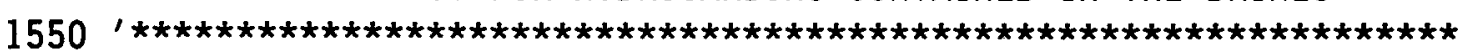

1560 PRINT

1570 INPUT "ENTER THE SLOPE OF THE EXTRACTED BENZENE CALIBRATION CURVE";BESLP

1580 PRINT

1590 INPUT "ENTER THE INTERCEPT OF THE EXTRACTED BENZENE CALIBRATION

CURVE" ; BEINT

1600 PRINT

1610 INPUT "ENTER THE A\% OF EXTRACTED BENZENE FROM THE GC";BE

1620 PRINT

1630 PRINT

$1640^{\prime * \star *}$ CALCULATION OF EXTRACTED BENZENE IN UL/L OF BRINE***

1650 IF BESLP $=0$ GOTO 1570

1660 BEULPL $=(B E-B E I N T) / B E S L P$

$1670 \mathrm{E} \$=$ "THE UL OF BENZENE/ L OF BRINE RECOVERED FROM THE BRINE IS "

1680 PRINT USING "\&";E\$; 
1690 PRINT USING "\#\#.\#\#";BEULPL;

1700 PRINT USING "\&";B\$

1710 PRINT

1720 PRINT

1730 INPUT "ENTER THE SLOPE OF THE EXTRACTED TOLUENE CALIBRATION CURVE"; TESLP

1740 PRINT

1750 INPUT "ENTER THE INTERCEPT OF THE EXTRACTED TOLUENE CALIBRATION CURVE"; TEINT

1760 PRINT

1770 INPUT "ENTER THE A\% EXTRACTED TOLUENE FROM THE GC"; TE

1780 PRINT

1790 PRINT

$1800^{\prime} \star \star \star *$ CALCULATION OF THE EXTRACTED TOLUENE IN UL/L OF BRINE***

1810 IF TESLP $=0$ GOTO 1730

1820 TEULPL $=($ TE-TEINT) $/$ TESLP

$1830 \mathrm{~F} \$=" T H E$ UL OF TOLUENE / L OF BRINE RECOVERED FROM THE BRINE IS "

1840 PRINT USING "\&"; F\$;

1850 PRINT USING "\#\#.\#\#";TEULPL;

1860 PRINT USING "\&";B\$

1870 PRINT

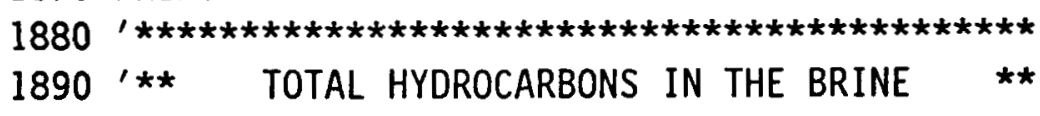

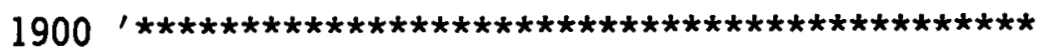

1910 PRINT

1920 TOTAL=ULPL+BWULPL+TWULPL+BEULPL+TEULPL

1930 G\$="THE TOTAL UL/L OF HYDROCARBONS IN THE BRINE IS "

1940 PRINT USING "\&";G\$;

1950 PRINT USING "\#\#.\#\#"TOTAL;

1960 PRINT USING "\&";B\$

1970 PRINT

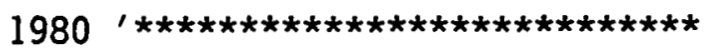

$1990^{\prime \prime} * *$ PRINTOUT OPTION $* *$

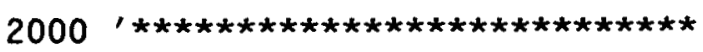

2010 PRINT

2020 PRINT "WOULD YOU LIKE TO HAVE A PRINTOUT OF THE RESULTS? (Y/N)" $2030 \mathrm{H} \$=$ INPUT $\$(1)$

2040 IF H\$="Y" THEN 2060 ELSE 2050

2050 IF $H \$=" y "$ THEN 2060 ELSE 2870

2060 LPRINT TAB(27) "CRYOGENINC CONDENSATE RESULTS"

2070 LPRINT:LPRINT:LPRINT

2080 IF I=1 GOTO 2090 ELSE 2110

2090 LPRINT TAB(10) "GLADYS MCCALL" TAB(61) SDATE\$

2100 GOTO 2120

2110 LPRINT TAB(10) "PLEASANT BAYOU" TAB(60) SDATE\$

2120 LPRINT 
2130 IF $Z=2$ GOTO 2590

2140 IF $Z=3$ GOTO 2590

2150 EE $\$="$ THE VOLUME OF CRYOGENIC CONDENSATE RECOVERED WAS "

$2160 \mathrm{FF} \$=" \mathrm{~mL} "$

2170 LPRINT TAB(10)

2180 LPRINT USING "\&"; EE\$;

2190 LPRINT USING "\#\#.\#\#";VCC;

2200 LPRINT USING "\&";FF\$

2210 LPRINT

2220 GG\$ $=$ "THE VOLUME OF GAS SAMPLED WAS "

$2230 \mathrm{HH} \$=" \mathrm{cu} \mathrm{ft}$ ○ $60 \mathrm{~F} \& 1 \mathrm{~atm} "$

2240 LPRINT TAB(10)

2250 LPRINT USING "\&";GG\$;

2260 LPRINT USING "\#\#\#.\#\#";VGAS;

2270 LPRINT USING "\&";HH\$

2280 LPRINT

2290 II $\$="$ THE BAROMETRIC PRESSURE WAS "

2300 JJ\$=" torrs"

2310 LPRINT TAB(10)

2320 LPRINT USING "\&"; II\$;

2330 LPRINT USING "\#\#\#\#";BP;

2340 LPRINT USING "\&";JJ\$

2350 LPRINT

$2360 \mathrm{KK} \$="$ THE AVERAGE COLLECTION TEMPERATURE WAS "

2370 LL $\$="$ DEGREES C"

2380 LPRINT TAB $(10)$

2390 LPRINT USING "\&"; KK\$;

2400 LPRINT USING "\#\#.\#"; TAVE-273.2;

2410 LPRINT USING "\&";LL\$

2420 LPRINT

2430 MM\$="THE BRINE TEMPERATURE WAS "

2440 NN\$=" DEGREES F OR "

2450 LPRINT TAB(10)

2460 LPRINT USING "\&";MM\$;

2470 LPRINT USING "\#\#\#:\#";TB;

2480 LPRINT USING "\&";NN\$;

2490 LPRINT USING "\#\#\#.\#";TC;

2500 LPRINT USING "\&";LL\$

2510 LPRINT

2520 00\$ $=$ "THE GAS/BRINE RATIO (WET) WAS "

2530 LPRINT TAB(10)

2540 LPRINT USING "\&";00\$;

2550 LPRINT USING "\#\#.\#";GBR;

2560 LPRINT USING "\&";HH\$

2570 LPRINT 
2580 LPRINT TAB(10) "THE SEPERATOR PRESSURE WAS";PS;"psi"

2590 LPRINT

2600 LPRINT TAB(10) "THE RESULTS ARE AS FOLLOWS; EXPRESSED AS UL/L OF BRINE:"

2610 LPRINT

2620 LPRINT

2630 AA\$ $\$$ "THE HYDROCARBONS FROM THE GAS ARE "

2640 LPRINT TAB(16);

2650 LPRINT USING "\&";AA\$;

2660 LPRINT USING "\#\#.\#\#";ULPL;

2670 LPRINT USING "\&";B\$

2680 LPRINT

2690 BB $\$=$ "THE HYDROCARBONS FROM THE WASH ARE "

2700 LPRINT TAB(16)

2710 LPRINT USING "\&";BB\$;

2720 LPRINT USING "\#\#.\#\#";BWULPL+TWULPL;

2730 LPRINT USING "\&";B\$

2740 LPRINT

2750 CC $\$="$ THE HYDROCARBONS FROM THE BRINE ARE "

2760 LPRINT TAB(16)

2770 LPRINT USING "\&"; CC\$;

2780 LPRINT USING "\#\#.\#\#";BEULPL+TEULPL;

2790 LPRINT USING "\&";B\$

2800 LPRINT TAB(52)

2810 TOTAL $=U L P L+B W U L P L+T W U L P L+B E U L P L+T E U L P L$

2820 DD $\$=" T H E$ TOTAL HYDROCARBONS ARE

2830 LPRINT TAB(16)

2840 LPRINT USING "\&";DD\$;

2850 LPRINT USING "\#\#.\#\#";TOTAL;

2860 LPRINT USING "\&";B\$

2870 END 

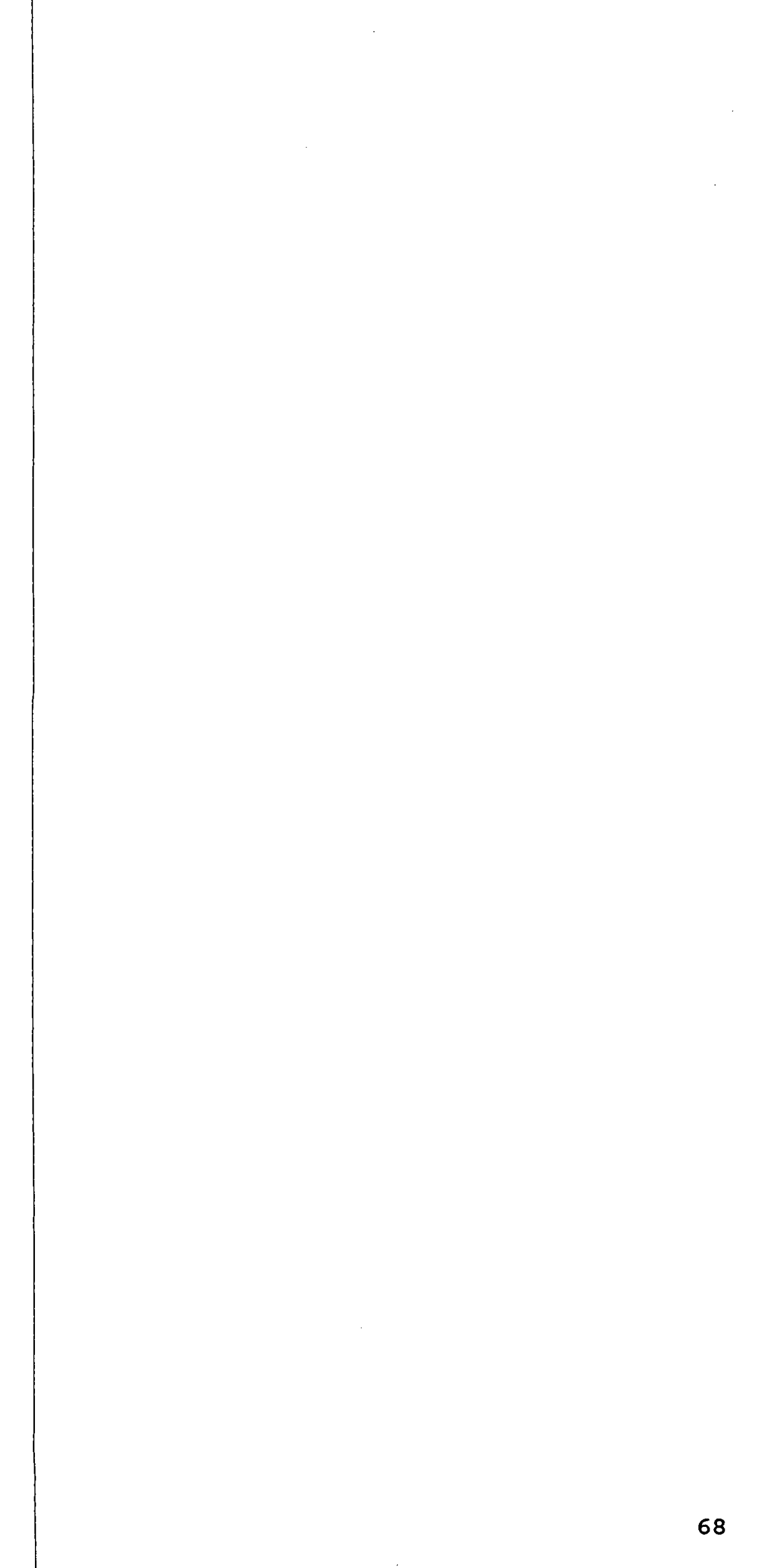

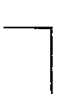




\section{Supplement A}

\section{Adsorption of Aromatic Compounds on Iron}

This supplement contains information, which although not one of our assigned tasks, we believe should be added to alert future researchers and/or other workers in the geothermal/geopressure field of a potential hazard.

While conducting other research, we have observed the adsorption of aromatic hydrocarbons, of the type present in the geothermal/geopressure cryocondensate, on iron surfaces. Figure $S .1$ summarizes our findings to date. The adsorption we have observed occurs on the kind of iron surface that would be found in steel pipe.

Since many of the cryocondensate components are known carcinogens, anyone working with steel pipe through which gas from any U.S. Gulf Coast geothermal/geopressure well has flowed should exercise caution in handing such pipe.

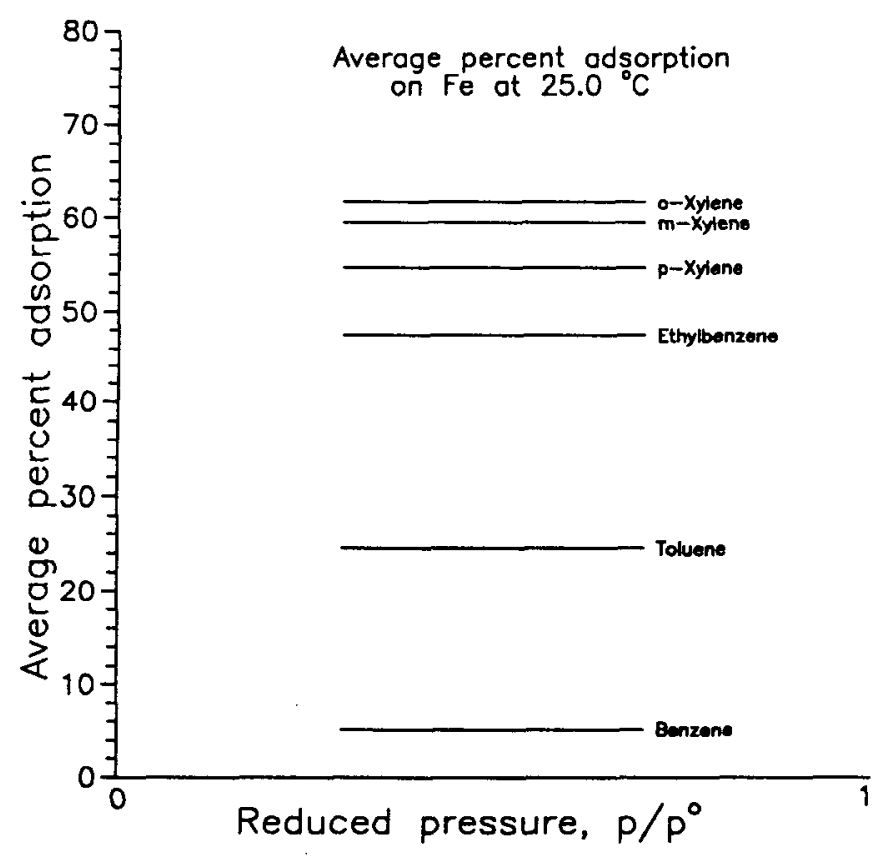

Figure S.1. Percent adsorption of benzene and its $c_{1}$ and $C_{2}$ alkylsubstited derivatives on iron as a function of reduced pressure $\left(p / p^{\circ}\right)$ at $25.0^{\circ} \mathrm{C}$. 
